\title{
Genomic variants link to hepatitis C racial disparities
}

Research Paper

\author{
Matthew M. Yeh ${ }^{1}$, Sarag Boukhar ${ }^{1}$, Benjamin Roberts ${ }^{2}$, Nairanjana Dasgupta ${ }^{3}$ and \\ Sayed S. Daoud ${ }^{4}$ \\ ${ }^{1}$ Department of Pathology, University of Washington School of Medicine, Seattle, WA 98195, USA \\ ${ }^{2}$ The Liver Center, University of Kansas Medical Center, Kansas City, KS 66160, USA \\ ${ }^{3}$ Department of Mathematics and Statistics, Washington State University, Pullman, WA 99164, USA \\ ${ }^{4}$ Department of Pharmaceutical Sciences, Washington State University Health Sciences, Spokane, WA 99210, USA \\ Correspondence to: Sayed S. Daoud, email: daoud@wsu.edu \\ Keywords: hepatitis C, racial disparity, genomic variants, hepatocellular carcinoma, alternative splicing \\ Received: November 30, $2016 \quad$ Accepted: July 03, 2017 Published: August 01, 2017 \\ Copyright: Yeh et al. This is an open-access article distributed under the terms of the Creative Commons Attribution License 3.0 \\ (CC BY 3.0), which permits unrestricted use, distribution, and reproduction in any medium, provided the original author and source \\ are credited.
}

\section{ABSTRACT}

Chronic liver diseases are one of the major public health issues in United States, and there are substantial racial disparities in liver cancer-related mortality. We previously identified racially distinct alterations in the expression of transcripts and proteins of hepatitis C (HCV)-induced hepatocellular carcinoma (HCC) between Caucasian (CA) and African American (AA) subgroups. Here, we performed a comparative genome-wide analysis of normal vs. HCV+ (cirrhotic state), and normal adjacent tissues (HCCN) vs. HCV+HCC (tumor state) of CA at the gene and alternative splicing levels using Affymetrix Human Transcriptome Array (HTA2.0). Many genes and splice variants were abnormally expressed in HCV+ more than in HCV+HCC state compared with normal tissues. Known biological pathways related to cell cycle regulations were altered in $\mathrm{HCV}+\mathrm{HCC}$, whereas acute phase reactants were deregulated in HCV+ state. We confirmed by quantitative RT-PCR that SAA1, PCNAAS1, DAB2, and IFI30 are differentially deregulated, especially in AA compared with CA samples. Likewise, IHC staining analysis revealed altered expression patterns of SAA1 and HNF4a isoforms in HCV+ liver samples of AA compared with CA. These results demonstrate that several splice variants are primarily deregulated in normal vs. HCV+ stage, which is certainly in line with the recent observations showing that the premRNA splicing machinery may be profoundly remodeled during disease progression, and may, therefore, play a major role in HCV racial disparity. The confirmation that certain genes are deregulated in AA compared to CA tissues also suggests that there is a biological basis for the observed racial disparities.

\section{INTRODUCTION}

Hepatocellular carcinoma (HCC) is one of the few malignancies in which the incidence is on the rise worldwide, especially in the US [1]. The increasing incidence of $\mathrm{HCC}$ in the US is associated with the rise in Hepatitis $\mathrm{C}$ virus (HCV) infection [2]. It is estimated that 3.2 million people in the US are infected with $\mathrm{HCV}$, a blood-borne disease linked to 12,000 US deaths a year [3]. Even with the availability of new oral direct acting antiviral drugs [4], it is anticipated that 320,000 patients will die from HCV, 157,000 will develop HCC, and 203,000 will develop cirrhosis in the next 35 years [5]. Inequalities in disease prevalence, treatment, and outcome make HCC an important health problem among minority groups [6]. First, there are disparities in the prevalence of $\mathrm{HCV}$ infection with African Americans (AA) being twice as likely to have been infected compared with Caucasian Americans (CA) [7]. Second, there are significant racial/ ethnic disparities in access to HCV care [8]. Third, African 
Americans are also less likely to respond to the new antiHCV therapy than Caucasian Americans, possibly due to a lower rate of sustained virologic response (SVR) [9], and have considerably lower likelihood of receiving liver transplantation [10]. While much of the existing literature so far has focused on noting the presence of these disparities, little is known about specific biological or genetic factors that are involved. Therefore, there is clear need for molecular/biological approaches to understand the molecular basis for HCV health and racial disparities. Ultimately positive outcomes would allow for the development of novel, affordable and much needed next generation therapeutic care management based on HCV disease state and the racial/ethnic background of patients [11]. We recently reported that racially distinct alterations in the expression of transcripts and proteins exist between CA and AA individuals infected with $\mathrm{HCV}$, as measured by proteomics-based analysis [12]. For example, we showed that the mRNA levels of transferrin $(T F)$, Apolipoprotein A1 (APOA1) and hepatocyte nuclear factor 4-alpha $(H N F 4 \alpha)$ were significantly altered in AA liver (cirrhotic) and tumor samples compared to CA. It is known that AA with chronic HCV commonly have elevated levels of serum markers of iron stores and altered cholesterol \& triglyceride levels $[13,14]$. The expression of TF \& APOA1 (both involved in iron homeostasis and lipid metabolic processes, respectively) is transcriptionally regulated by $H N F 4 \alpha[15,16]$. Furthermore, $H N F 4 \alpha$ is also known to be involved in the pathogenesis of HCC $[17,18]$. To the best of our knowledge, that was the first study to demonstrate possible link between deregulation of the expression of specific transcripts \& proteins and $\mathrm{HCV}$ racial disparity between $\mathrm{AA}$ and $\mathrm{CA}$ subgroups. This finding prompted us to further investigate whether alternative splicing (AS) of genes could be involved in the transcriptome diversity seen between these two ethnic populations. Alternative splicing (AS) is a posttranscriptional event whereby exons are joined by different combinations generating various isoforms from a single gene [19-21]. It has been shown that most genes have at least 2 alternative isoforms [22, 23] contributing to both transcriptome and proteome diversities in various pathophysiological situations including $\mathrm{HCV}$ infection and HCC $[24,25]$.

In this study, we have performed a genome-wide transcriptomic analysis at the gene and splice variants levels in liver and tumor tissue samples of HCV infected individuals using the Affymetrix GeneChip Human Transcriptome array (HTA2.0). The array is especially designed to allow for expression profiling of transcript splice variants. It contains $>6.0$ million probes covering coding transcripts $(70 \%)$ and exon-exon splice junctions and non-coding transcripts $(30 \%)$. Herein, we describe our methods for expression microarray analysis at the genes and splice variants levels using Transcriptome Analysis Console (TAC2.0) software coupled by validation studies to confirm disease-specific splice variants of genes that could be involved in the racial disparity of HCV-induced HCC by real-time qRT-PCR and immunohistochemistry using sixty liver and tumor tissue samples.

\section{RESULTS}

\section{Clinical characteristics of tissue samples}

A total of 36 snapped frozen liver and tumor samples from CA and AA populations were used in this study. The clinicopathologic characteristics of samples are presented in Supplementary Table 2. As reported in our previous study [12], there were no significant differences of age and sex between samples in the two groups. However, the cirrhotic HCV+ liver samples of AA group had statistically significant laboratory results for aspartate aminotransferase (AST), and alanine aminotransferase (ALT) $(p<0.05)$ compared to CA group. There were no significance differences in the laboratory values for albumin, total albumin and hemoglobin between samples in the two groups.

\section{Identification of differentially expressed genes and splice variants based on diseased states of Caucasian American (CA) population}

Gene level differential expression profiles of $12 \mathrm{CA}$ tissues samples ( 3 normal liver, $3 \mathrm{HCV}+$ livers, $3 \mathrm{HCV}+/$ $\mathrm{HCC}+$ tumors and $3 \mathrm{HCCN}$ ) were determined using HTA2.0 GeneChip Arrays (Affymetrix ${ }^{\circledR}$ ) that contain 70,523 detectable transcripts using TAC2.0 software (for filtering criteria see Materials and methods). For normal $v s . \mathrm{HCV}+, 636$ genes were differentially expressed: 350 genes were up-regulated in $\mathrm{HCV}+$ compared to normal (coding 235; non-coding 103; other 12) as shown in Table $1 \mathrm{~A}$, whereas 286 genes were down-regulated in $\mathrm{HCV}+$ compared to normal (coding 209; non-coding 73; other 4), Table 1B. For HCCN vs. HCV+HCC, only 61 genes were differentially expressed, as shown in Table 2, using the same algorithm options and filter criteria (see Materials and methods): 47 genes were up-regulated in $\mathrm{HCV}+\mathrm{HCC}$ compared to HCCN (coding 23; non-coding 6; other 18) and 14 genes were down-regulated in $\mathrm{HCV}+\mathrm{HCC}$ compared to HCCN (coding 5; non-coding 1; other 8). These results suggest that tumor-adjacent tissue ( $\mathrm{HCCN})$ shares biology of the tumors themselves, and only 61 genes are differentially expressed in this case. Figure 1 shows the scatter plot ( $\log 2$ scale of expression values) for differentially expressed genes (DEGs) in normal $v s$. HCV+ state (Figure $1 \mathrm{~A}$ ) and $\mathrm{HCCN} v s . \mathrm{HCV}+\mathrm{HCC}$ state (Figure 1B), respectively. In both cases, most of the genes run along the diagonal axis and can be considered as common genes, expressed similarly in either diseased state, whereas differentially expressed genes with values $<-2.0$ or $<+2.0$ are scattered outside the diagonal axis. Examples of these 
Table 1A: The results of differentially expressed genes (DEGs) in normal vs. HCV+ tissue samples

\begin{tabular}{|c|c|c|c|c|c|}
\hline Accession Number & Fold Change & Fold Direction & $p$ value & Gene Symbol & Group \\
\hline NM_000706 & 13.8 & N UP vs. HCV & 0.01640 & AVPR1A & Coding \\
\hline NM_030754 & 12.05 & N UP vs. HCV & 0.00282 & SAA2 & Coding \\
\hline NM_005949 & 9.48 & N UP vs. HCV & 0.04235 & MT1F & Coding \\
\hline NM_030787 & 6.01 & N UP vs. HCV & 0.00645 & CFHR5 & Coding \\
\hline NM_014926 & 5.96 & N UP vs. HCV & 0.01872 & SLITRK3 & Coding \\
\hline NM_001144904 & 5.79 & N UP vs. HCV & 0.03399 & CLEC4M & Coding \\
\hline NM_000331 & 5.13 & N UP vs. HCV & 0.01927 & SAA1 & Coding \\
\hline NM_001166624 & 5.08 & N UP vs. HCV & 0.01142 & CFHR3 & Coding \\
\hline NM_001201550 & 4.99 & N UP vs. HCV & 0.02009 & CFHR4 & Coding \\
\hline NM_176870 & 4.45 & N UP vs. HCV & 0.02094 & MT1M & Coding \\
\hline NM_001308 & 3.97 & N UP vs. HCV & 0.03343 & CPN1 & Coding \\
\hline NM_001146726 & 3.93 & N UP vs. HCV & 0.00794 & TIMD4 & Coding \\
\hline NM_145290 & 3.68 & N UP vs. HCV & 0.00611 & GPR125 & Coding \\
\hline NM_031900 & 3.62 & N UP vs. HCV & 0.01828 & AGXT2 & Coding \\
\hline NM_020459 & 3.54 & N UP vs. HCV & 0.02778 & PAIP2B & Coding \\
\hline NM_032649 & 3.52 & N UP vs. HCV & 0.00289 & CNDP1 & Coding \\
\hline NM_001159 & 3.45 & N UP vs. HCV & 0.02937 & AOX1 & Coding \\
\hline NM_001361 & 3.31 & N UP vs. HCV & 0.01586 & DHODH & Coding \\
\hline NM_006419 & 3.3 & N UP vs. HCV & 0.00101 & CXCL13 & Coding \\
\hline NM_001039199 & 3.29 & N UP vs. HCV & 0.00756 & TTPAL & Coding \\
\hline NM_001127708 & 3.29 & N UP vs. HCV & 0.03135 & PRG4 & Coding \\
\hline NM_001193646 & 3.28 & N UP vs. HCV & 0.04037 & ATF5 & Coding \\
\hline NM_001143838 & 3.27 & N UP vs. HCV & 0.04855 & SLC13A5 & Coding \\
\hline NM_052972 & 3.25 & N UP vs. HCV & 0.00249 & LRG1 & Coding \\
\hline NM_000028 & 3.2 & N UP vs. HCV & 0.00334 & AGL & Coding \\
\hline NM_000055 & 3.11 & N UP vs. HCV & 0.01262 & BCHE & Coding \\
\hline NM_175737 & 3.09 & N UP vs. HCV & 0.02281 & KLB & Coding \\
\hline NM_000902 & 2.99 & N UP vs. HCV & 0.00453 & MME & Coding \\
\hline NM_016371 & 2.97 & N UP vs. HCV & 0.04476 & HSD17B7 & Coding \\
\hline NM_018078 & 2.95 & N UP vs. HCV & 0.04017 & LARP1B & Coding \\
\hline NM_000133 & 2.93 & N UP vs. HCV & 0.04671 & F9 & Coding \\
\hline NM_001170701 & 2.9 & N UP vs. HCV & 0.00523 & MBLN3 & Coding \\
\hline NM_004944 & 2.89 & N UP vs. HCV & 0.03243 & DNASE1L3 & Coding \\
\hline NM_006691 & 2.81 & N UP vs. HCV & 0.00779 & LYVE1 & Coding \\
\hline NM_014465 & 2.79 & N UP vs. HCV & 0.00251 & SULT1B1 & Coding \\
\hline NM_001161429 & 2.7 & N UP vs. HCV & 0.00854 & RANBP3L & Coding \\
\hline NM_006770 & 2.69 & N UP vs. HCV & 0.01995 & MARCO & Coding \\
\hline
\end{tabular}




\begin{tabular}{|c|c|c|c|c|c|}
\hline Accession Number & Fold Change & Fold Direction & $p$ value & Gene Symbol & Group \\
\hline NM_001174152 & 2.68 & N UP vs. HCV & 0.00824 & RABEPK & Coding \\
\hline NM_001130991 & 2.62 & N UP vs. HCV & 0.00355 & HYOU1 & Coding \\
\hline NM_033058 & 2.59 & N UP vs. HCV & 0.04228 & TRIM55 & Coding \\
\hline NM_001123 & 2.54 & N UP vs. HCV & 0.02600 & $\mathrm{ADK}$ & Coding \\
\hline NM_004169 & 2.52 & N UP vs. HCV & 0.00361 & SHMT1 & Coding \\
\hline NM_005907 & 2.5 & N UP vs. HCV & 0.00967 & MAN1A1 & Coding \\
\hline NM_001128431 & 2.5 & N UP vs. HCV & 0.01099 & SLC39A14 & Coding \\
\hline NM_001128227 & 2.5 & N UP vs. HCV & 0.01359 & GNE & Coding \\
\hline NM_001737 & 2.49 & N UP vs. HCV & 0.01724 & C9 & Coding \\
\hline NM_004911 & 2.47 & N UP vs. HCV & 0.00481 & PDIA4 & Coding \\
\hline NM_000019 & 2.47 & N UP vs. HCV & 0.00874 & ACAT1 & Coding \\
\hline NM_005768 & 2.47 & N UP vs. HCV & 0.03440 & LPCAT3 & Coding \\
\hline NM_000066 & 2.47 & N UP vs. HCV & 0.04159 & $\mathrm{C} 8 \mathrm{~B}$ & Coding \\
\hline NM_000478 & 2.46 & N UP vs. HCV & 0.00447 & ALPL & Coding \\
\hline NM_145715 & 2.44 & N UP vs. HCV & 0.01064 & TIGD2 & Coding \\
\hline NM_004481 & 2.43 & N UP vs. HCV & 0.03059 & GALNT2 & Coding \\
\hline NM_000236 & 2.43 & N UP vs. HCV & 0.03763 & LIPC & Coding \\
\hline NM_004475 & 2.39 & N UP vs. HCV & 0.00135 & FLOT2 & Coding \\
\hline NM_014730 & 2.38 & N UP vs. HCV & 0.00073 & MLEC & Coding \\
\hline NM_138326 & 2.38 & N UP vs. HCV & 0.03850 & ACMSD & Coding \\
\hline NM_015541 & 2.37 & N UP vs. HCV & 0.04555 & LRIG1 & Coding \\
\hline NM_003658 & 2.36 & N UP vs. HCV & 0.02789 & MT1DP & Coding \\
\hline NM_004108 & 2.34 & N UP vs. HCV & 0.01438 & FCN2 & Coding \\
\hline NM_001242332 & 2.32 & N UP vs. HCV & 0.00197 & USP17L6P & Coding \\
\hline NM_000715 & 2.32 & N UP vs. HCV & 0.02707 & C4BPA & Coding \\
\hline NM_001199758 & 2.31 & N UP vs. HCV & 0.00640 & MTHF5 & Coding \\
\hline NM_001144978 & 2.31 & N UP vs. HCV & 0.00910 & MTHFD2L & Coding \\
\hline NM_181536 & 2.31 & N UP vs. HCV & 0.02866 & PKD1L3 & Coding \\
\hline NM_004388 & 2.3 & N UP vs. HCV & 0.00628 & CTBS & Coding \\
\hline NM_005570 & 2.3 & N UP vs. HCV & 0.01109 & LMAN1 & Coding \\
\hline NM_002168 & 2.29 & N UP vs. HCV & 0.00779 & IDH2 & Coding \\
\hline NM_000348 & 2.27 & N UP vs. HCV & 0.01335 & SRD5A2 & Coding \\
\hline NM_000240 & 2.27 & N UP vs. HCV & 0.02094 & MAO2 & Coding \\
\hline NM_001859 & 2.27 & N UP vs. HCV & 0.03664 & SLC31A1 & Coding \\
\hline NM_005691 & 2.26 & N UP vs. HCV & 0.00742 & ABCC 9 & Coding \\
\hline NM_001005375 & 2.26 & N UP vs. HCV & 0.03061 & DAZ4 & Coding \\
\hline NM_000562 & 2.25 & N UP vs. HCV & 0.04361 & $\mathrm{C} 8 \mathrm{~A}$ & Coding \\
\hline NM_000065 & 2.23 & N UP vs. HCV & 0.04204 & C6 & Coding \\
\hline
\end{tabular}

(Continued) 


\begin{tabular}{lcllcc}
\hline Accession Number & Fold Change & Fold Direction & $\boldsymbol{p}$ value & Gene Symbol & Group \\
\hline NM_000608 & 2.22 & N UP vs. HCV & 0.01256 & ORM2 & Coding \\
NM_039654 & 2.22 & N UP vs. HCV & 0.02000 & MIR4450 & Coding \\
NM_005794 & 2.21 & N UP vs. HCV & 0.00033 & DHRS2 & Coding \\
NM_022132 & 2.19 & N UP vs. HCV & 0.01297 & MCCC2 & Coding \\
NM_030782 & 2.18 & N UP vs. HCV & 0.00912 & CLPTM1L & Coding \\
NM_182758 & 2.18 & N UP vs. HCV & 0.01132 & WDR72 & Coding \\
NM_001014797 & 2.16 & N UP vs. HCV & 0.00922 & KCNMA1 & Coding \\
NM_006741 & 2.16 & N UP vs. HCV & 0.01382 & PPP1R1A & Coding \\
NM_181900 & 2.16 & N UP vs. HCV & 0.03056 & STARD5 & Coding \\
NM_005013 & 2.14 & N UP vs. HCV & 0.02120 & NUCB2 & Coding \\
NM_001918 & 2.13 & N UP vs. HCV & 0.03126 & DBT & Coding \\
NM_001161504 & 2.11 & N UP vs. HCV & 0.02578 & ALDH4A1 & Coding \\
NM_001015880 & 2.1 & N UP vs. HCV & 0.00207 & PAPSS2 & Coding \\
NM_001100607 & 2.1 & N UP vs. HCV & 0.01792 & SERPINA10 & Coding \\
NM_001145368 & 2.08 & N UP vs. HCV & 0.00871 & PTPN3 & Coding \\
NM_005045 & 2.07 & N UP vs. HCV & 0.00942 & RELN & Coding \\
NM_138493 & 2.06 & N UP vs. HCV & 0.00822 & CCDC167 & Coding \\
NR_029524 & 2.06 & N UP vs. HCV & 0.01216 & MIR107 & Coding \\
NM_001113239 & 2.02 & N UP vs. HCV & 0.00036 & HIPK2 & Coding \\
NM_003878 & 2.02 & N UP vs. HCV & 0.00058 & GGH & Coding \\
NM_001872 & 2.01 & N UP vs. HCV & 0.04171 & CPB2 & Coding \\
NM_021800 & 2.01 & N UP vs. HCV & 0.04931 & DNAJC12 & Coding \\
\hline
\end{tabular}

Table 1B: The results of differentially expressed genes (DEGs) in HCV+ vs. Normal tissue samples

\begin{tabular}{lccccc}
\hline Accession Number & Fold Change & Fold Direction & $\boldsymbol{p}$ value & Gene Symbol & Group \\
\hline NM_020299 & -30.81 & HCV UP vs. N & 0.00242 & AKR1B10 & Coding \\
NM_001130080 & -14.86 & HCV UP vs. N & 0.02019 & IFI27 & Coding \\
NM_000584 & -8.33 & HCV UP vs. N & 0.03313 & IL8 & Coding \\
NR_026703 & -7.05 & HCV UP vs. N & 0.02314 & VTRNA1-1 & Coding \\
NM_000582 & -6.02 & HCV UP vs. N & 0.03381 & SPP1 & Coding \\
NM_004864 & -5.65 & HCV UP vs. N & 0.00097 & GDF15 & Coding \\
NM_033049 & -5.46 & HCV UP vs. N & 0.03079 & MUC13 & Coding \\
NM_001040092 & -4.93 & HCV UP vs. N & 0.00379 & ENPP2 & Coding \\
NM_001565 & -4.79 & HCV UP vs. N & 0.00803 & CXCL10 & Coding \\
NM_006149 & -3.89 & HCV UP vs. N & 0.00061 & LGALS4 & Coding \\
NM_001046 & -3.84 & HCV UP vs. N & 0.02276 & SLC12A2 & Coding
\end{tabular}

(Continued) 


\begin{tabular}{|c|c|c|c|c|c|}
\hline Accession Number & Fold Change & Fold Direction & $p$ value & Gene Symbol & Group \\
\hline NR_002921 & -3.83 & HCV UP vs. N & 0.00306 & SNORA75 & Coding \\
\hline NM_006398 & -3.77 & HCV UP vs. N & 0.04837 & UBD & Coding \\
\hline NM_025130 & -3.66 & HCV UP vs. N & 0.02106 & $\mathrm{HKDC1}$ & Coding \\
\hline NM_000492 & -3.61 & HCV UP vs. N & 0.00914 & CFTR & Coding \\
\hline NM_000552 & -3.59 & HCV UP vs. N & 0.00285 & VWF & Coding \\
\hline NR_002953 & -3.45 & HCV UP vs. N & 0.00506 & SNORA11 & Coding \\
\hline NM_001128175 & -3.39 & HCV UP vs. N & 0.00364 & DTNA & Coding \\
\hline NM_031310 & -3.38 & HCV UP vs. N & 0.00235 & PLVAP & Coding \\
\hline AF533910 & -3.33 & HCV UP vs. N & 0.04893 & HLA-DQA1 & Coding \\
\hline NR_002915 & -3.3 & HCV UP vs. N & 0.00041 & SNORA74A & Coding \\
\hline NM_001166395 & -3.29 & HCV UP vs. N & 0.00387 & CHST4 & Coding \\
\hline AF287958 & -3.29 & HCV UP vs. N & 0.01057 & HLA-A & Coding \\
\hline NM_016591 & -3.26 & HCV UP vs. N & 0.03060 & $\mathrm{BICC} 1$ & Coding \\
\hline NM_005245 & -3.21 & HCV UP vs. N & 0.01618 & FAT1 & Coding \\
\hline NM_144975 & -3.2 & HCV UP vs. N & 0.01512 & SLFN5 & Coding \\
\hline NM_021983 & -3.11 & HCV UP vs. N & 0.01176 & HLA-DRB4 & Coding \\
\hline NR_003016 & -3.09 & HCV UP vs. N & 0.02789 & SNORA26 & Coding \\
\hline NM_005567 & -3.05 & HCV UP vs. N & 0.00582 & LGALS3BP & Coding \\
\hline NM_020638 & -3.03 & HCV UP vs. N & 0.02594 & FGF23 & Coding \\
\hline NM_006274 & -2.95 & HCV UP vs. N & 0.00198 & CCL19 & Coding \\
\hline NM_001901 & -2.87 & HCV UP vs. N & 0.04083 & CTGF & Coding \\
\hline NM_001144964 & -2.84 & HCV UP vs. N & 0.00177 & NEDD4L & Coding \\
\hline NM_001003954 & -2.81 & HCV UP vs. N & 0.00160 & ANXA13 & Coding \\
\hline NM_017533 & -2.81 & HCV UP vs. N & 0.02032 & MYH4 & Coding \\
\hline NM_005961 & -2.73 & HCV UP vs. N & 0.00874 & MUC6 & Coding \\
\hline NM_002345 & -2.72 & HCV UP vs. N & 0.02683 & LUM & Coding \\
\hline NM_001164617 & -2.71 & HCV UP vs. N & 0.03061 & GPC3 & Coding \\
\hline NM_138694 & -2.68 & HCV UP vs. N & 0.00081 & PKHD1 & Coding \\
\hline NM_001206567 & -2.68 & HCV UP vs. N & 0.00272 & IFI16 & Coding \\
\hline NM_001242758 & -2.68 & HCV UP vs. N & 0.00823 & HLA-A & Coding \\
\hline NM_002354 & -2.68 & HCV UP vs. N & 0.02366 & EPCAM & Coding \\
\hline NM_005218 & -2.59 & HCV UP vs. N & 0.03577 & DEFB1 & Coding \\
\hline NM_001781 & -2.58 & HCV UP vs. N & 0.03613 & CD69 & Coding \\
\hline NM_016548 & -2.57 & HCV UP vs. N & 0.00153 & GOLM1 & Coding \\
\hline NM_000587 & -2.52 & HCV UP vs. N & 0.01468 & $\mathrm{C} 7$ & Coding \\
\hline NM_002867 & -2.47 & HCV UP vs. N & 0.03684 & RAB3B & Coding \\
\hline
\end{tabular}




\begin{tabular}{|c|c|c|c|c|c|}
\hline Accession Number & Fold Change & Fold Direction & $p$ value & Gene Symbol & Group \\
\hline NM_001546 & -2.46 & HCV UP vs. N & 0.00355 & ID4 & Coding \\
\hline NM_005233 & -2.45 & HCV UP vs. N & 0.01517 & EPHA3 & Coding \\
\hline NM_005261 & -2.43 & HCV UP vs. N & 0.01036 & GEM & Coding \\
\hline NM_002989 & -2.42 & HCV UP vs. N & 0.00164 & CCL21 & Coding \\
\hline NM_002416 & -2.37 & HCV UP vs. N & 0.02732 & CXCL9 & Coding \\
\hline NM_005556 & -2.37 & HCV UP vs. N & 0.02828 & KRT7 & Coding \\
\hline NM_138788 & -2.34 & HCV UP vs. N & 0.00009 & TMEM45B & Coding \\
\hline NM_015529 & -2.34 & HCV UP vs. N & 0.03311 & MOXD1 & Coding \\
\hline NM_032211 & -2.28 & HCV UP vs. N & 0.00438 & LOXL4 & Coding \\
\hline NM_000346 & -2.28 & HCV UP vs. N & 0.00737 & SOX9 & Coding \\
\hline NM_173648 & -2.25 & HCV UP vs. N & 0.00153 & CCDC141 & Coding \\
\hline NM_003319 & -2.25 & HCV UP vs. N & 0.00285 & TTN & Coding \\
\hline NM_003246 & -2.23 & HCV UP vs. N & 0.03008 & THBS1 & Coding \\
\hline NM_000366 & -2.23 & HCV UP vs. N & 0.04147 & TPM1 & Coding \\
\hline NM_001198695 & -2.17 & HCV UP vs. N & 0.00717 & MFAP4 & Coding \\
\hline NM_001128310 & -2.17 & HCV UP vs. N & 0.01904 & SPARCL1 & Coding \\
\hline NM_001105549 & -2.16 & HCV UP vs. N & 0.00629 & ZNF83 & Coding \\
\hline NM_003897 & -2.15 & HCV UP vs. N & 0.01088 & IER3 & Coding \\
\hline NM_004791 & -2.15 & HCV UP vs. N & 0.04359 & ITGBL1 & Coding \\
\hline NM_001005180 & -2.14 & HCV UP vs. N & 0.00085 & TRIM22 & Coding \\
\hline NM_018420 & -2.14 & HCV UP vs. N & 0.01240 & SLC22A15 & Coding \\
\hline NM_005841 & -2.14 & HCV UP vs. N & 0.01787 & SPRY1 & Coding \\
\hline NM_182832 & -2.14 & HCV UP vs. N & 0.04488 & PLAC4 & Coding \\
\hline NM_002392 & -2.13 & HCV UP vs. N & 0.00520 & MDM2 & Coding \\
\hline NM_001080538 & -2.13 & HCV UP vs. N & 0.01548 & AKR1B15 & Coding \\
\hline NM_014314 & -2.13 & HCV UP vs. N & 0.02827 & DDX58 & Coding \\
\hline NM_000141 & -2.09 & HCV UP vs. N & 0.00133 & FGFR2 & Coding \\
\hline NM_006291 & -2.09 & HCV UP vs. N & 0.03200 & TNFAIP2 & Coding \\
\hline NM_001129 & -2.07 & HCV UP vs. N & 0.04471 & AEBP1 & Coding \\
\hline NM_001005473 & -2.06 & HCV UP vs. N & 0.02827 & PLCXD3 & Coding \\
\hline NM_014256 & -2.06 & HCV UP vs. N & 0.04406 & B3GNT3 & Coding \\
\hline NM_144682 & -2.05 & HCV UP vs. N & 0.00055 & SLFN13 & Coding \\
\hline NM_198281 & -2.05 & HCV UP vs. N & 0.01338 & GPRIN3 & Coding \\
\hline NM_001098484 & -2.02 & HCV UP vs. N & 0.01968 & SLC4A4 & Coding \\
\hline NM_001253835 & -2.01 & HCV UP vs. N & 0.03487 & IGFBP7 & Coding \\
\hline
\end{tabular}


Table 2: The results of differentially expressed genes (DEGs) in HCC vs. HCCN samples

\begin{tabular}{lccccc}
\hline Accession Number & Fold Change & Fold Direction & $\boldsymbol{p}$ value & Gene Symbol & Group \\
\hline NR_028370 & 3.53 & HCC UP vs. HCCN & 0.04806 & PCNA-AS1 & Coding \\
NM_080593 & 2.35 & HCC UP vs. HCCN & 0.04926 & HIST1H2BK & Coding \\
NM_006332 & 2.21 & HCC UP vs. HCCN & 0.04400 & IFI30 & Coding \\
NM_001145845 & 2.2 & HCC UP vs. HCCN & 0.03077 & ROBO1 & Coding \\
NM_001244871 & 2.11 & HCC UP vs. HCCN & 0.04974 & DAB2 & Coding \\
NR_039890 & 2.01 & HCC UP vs. HCCN & 0.03285 & MIR4737 & Coding \\
NR_004398 & -2.20 & HCC UP vs. HCCN & 0.01972 & SNORD82 & Coding \\
\hline
\end{tabular}

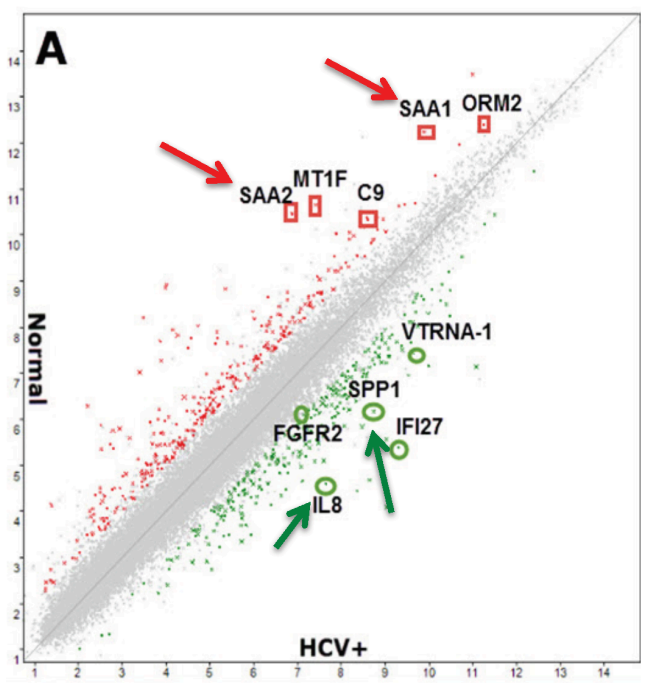

Insert IC: $\log _{2}$ values corresponding to top 10 DEGs in Normal vs. HCV+

\begin{tabular}{|l|l|l|}
\hline Differentially Expressed Genes & Normal & HCV+ (cirrhotic) \\
\hline AVPR1A & & \\
\hline SAA2 & 7.94 & 4.15 \\
\hline MT1F & 10.46 & 6.87 \\
\hline HA02-IT1 & 10.65 & 7.41 \\
\hline CFHR5 & 7.77 & 4.57 \\
\hline AKR1B10 & 7.76 & 5.17 \\
\hline IFI27 & 4.68 & 8.64 \\
\hline IL8 & 5.39 & 9.29 \\
\hline VTRNA-1 & 4.59 & 7.65 \\
\hline SPP1 & 7.17 & 9.99 \\
\hline
\end{tabular}

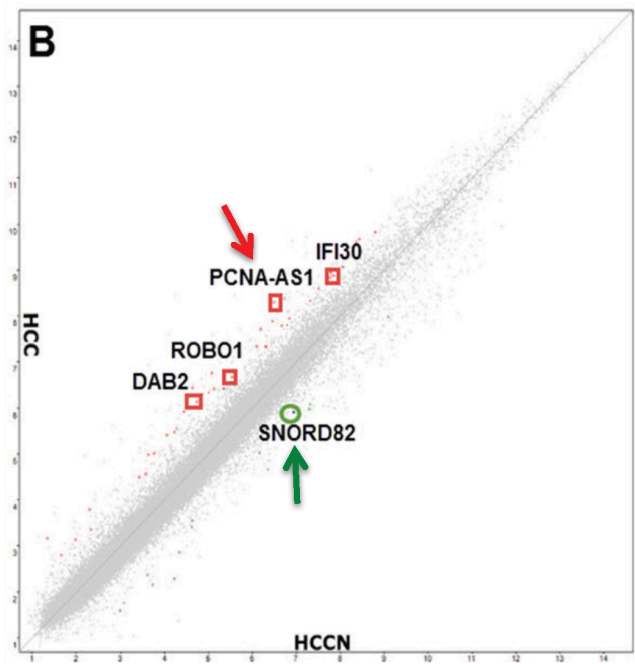

Insert D: $\log _{2}$ values corresponding to top 7 DEGs in HCCN vs. HCC

\begin{tabular}{|l|l|l|}
\hline Differentially Expressed Genes & HCCN & HCC \\
\hline PCNA-AS1 & & \\
\hline HIST1H2BK & 6.19 & 7.72 \\
\hline IFI30 & 8.44 & 9.67 \\
\hline ROBO1 & 7.79 & 8.94 \\
\hline DAB2 & 5.54 & 6.68 \\
\hline MIR4737 & 5.35 & 6.42 \\
\hline SNORD82 & 7.32 & 8.33 \\
\hline
\end{tabular}

Figure 1: Global gene expression profiling data of hepatitis $\mathbf{C}$ tissue samples. (A): Scatter plot presenting the values of $\log _{2}$ for each gene in the normal (Y-axis) vs. HCV+ cirrhotic samples (X-axis). (B): Scatter plot presenting the values of $\log _{2}$ for each gene in the HCCN (X-axis) vs. HCV+HCC tumor samples (Y-axis). Insert (C): Table indicating the log2 values corresponding to top 10 DEGs in normal $v s$. HCV+ samples. Insert (D): Table indicating the log2 values corresponding to top 7 DEGs in HCCN $v s$. HCV+ HCC samples. 
scattered genes (arrows) are shown in Figure 1A (insert $1 \mathrm{C}$ ) and Figure 1B (insert $1 \mathrm{D})$. No overlap of genes (marked) was detected between the two disease stages, which suggest that these genes are differentially expressed based on disease state (normal vs. HCV+ cirrhotic livers; $\mathrm{HCCN} v s . \mathrm{HCV}+/ \mathrm{HCC}$ cirrhotic tumors).

For alternative splicing analysis, based on the algorithm options and filter criteria stated in the materials and methods, we were able to detect splice variant events only in normal vs. HCV+ stage (cirrhotic) and not in $\mathrm{HCCN} v s . \mathrm{HCV}+\mathrm{HCC}$ stage (tumor). This could be due to the low numbers of DEGs detected in the tumor state (61 genes) and/or the cut off and filter criteria. However, in normal vs. HCV+ stage about 12,650 genes were expressed in both conditions (coding). Only $15 \%$ of genes have at least one PSR or junction with SI (linear) $<-2.0$ or $>+2.0$ to indicate alternative splicing. For non-coding, about 2,943 of genes were expressed in both conditions. Only $2.7 \%$ of genes were found to have at least one PSR or junction with SI (linear) $<-2.0$ or $>+2.0$ to indicate alternative splicing. Table 3 shows various alternative splicing events (coding) for the top 30 genes identified in normal vs. HCV+ livers.

\section{Differentially expressed genes are involved in a number of pathways and networks associated with disease state}

To gain insights into the molecular pathways involving the identified differentially expressed genes, Ingenuity Pathway Analysis (IPA) of experimental data was performed by Ingenuity software as we previously reported [12]. Using the list of 636 genes involved in normal vs. HCV+ (cirrhotic) events and 61 genes involved in HCCN vs. HCV+HCC (tumor) events, IPA identified several pathways and function that might be relevant for each disease stage as shown in Tables 4A and $4 \mathrm{~B}$, respectively. Top associated network functions for differentially expressed genes in $\mathrm{HCV}+$ cirrhotic state (Table 4A) were: 1) Hepatic fibrosis/hepatic stellate cell activation, 2) Antigen presentation pathway, 3) Graftversus-host disease signaling, 4) Inhibition of matrix metalloproteases, and 5) T-helper cell differentiation. These data suggest that acute inflammatory phase is involved in $\mathrm{HCV}+$ cirrhotic state as a result of $\mathrm{HCV}$ induced oxidative stress. Genes such as $S A A 1, S A A 2$ and LGALS4 known to be involved in acute inflammatory phase were detected in this disease state (Tables 1A and 1B; Figure 1A). For HCCN vs. HCV+HCC (tumor stage), top associated network functions for differentially expressed genes (Table 4B) were: 1) GADD 45 signaling, 2) Cell cycle control of chromosomal replication, 3) Estrogen-mediated S-phase entry, 4) Cell cycle: G2/M DNA damage checkpoint regulation, 5) Cyclins and cell cycle regulation. These data suggest that cell cycle signaling pathways are certainly involved in $\mathrm{HCV}$-induced
HCC (tumor phase). Genes such as PCNA-AS1 and $H I S T 1 H 2 B K$ known to be involved in cell cycle regulation pathways were detected in this disease stage (Table 2; Figure 1B).

\section{Target validation of gene expression and splice variants in Caucasian and African Americans tissue samples}

In order to determine whether the racial disparity seen in $\mathrm{HCV}$ associated $\mathrm{HCC}$ is partly due to the diversity in gene expression and splice variants events between $\mathrm{CA}$ and $\mathrm{AA}$, we selected a representative group of genes for qRT-PCR cross validation analysis. For normal $v s$. $\mathrm{HCV}+$ (cirrhotic state), we selected the following genes: SAA1, AOX1 and SLC13A5. Representative examples of the amplicon binding sites for the PCR primer sequences are shown in Supplementary Figures 1 and 2. For $\mathrm{HCCN} v s$. $\mathrm{HCV}+\mathrm{HCC}$ (tumor stage), the following genes were selected: PCNA-AS1, IFI30, DBA2, ROBO1, and SNORD82. The expression of these eight genes was validated by qRT-PCR using an independent test set of 24 liver and tumor tissue samples (12 CA and $12 \mathrm{AA}$ ). The qRT-PCR results are shown in Tables 5A and 5B. The data suggest that good concordance of the results is seen using HTA2.0 arrays and qRT-PCR analysis. However, there is a distinct difference in $S A A 1$ expression level between CA \& AA samples (Table 5A). The overall fold change (FC) of $S A A 1$ in CA samples has a positive value because the overall gene expression in $\mathrm{HCV}+$ cirrhotic liver is down compared to normal (Table 1A) resulting in a positive fold-change (FC) value. Although the overall FC (qRTPCR) in AA samples (Table 5A) has a positive value, it is actually lower than CA, because the overall gene expression in $\mathrm{HCV}+$ cirrhotic liver is higher in $\mathrm{CA}$, thus lower value of FC is seen. Similar profile is seen in genes expressed in $\mathrm{HCCN} v s$. $\mathrm{HCV}+\mathrm{HCC}$ (tumor state): PCNA$A S 1, R O B O 1, D A B 2$, and IFI30 (Table 5A, lower part). As shown in Table 5B, SAA1 has an overall SI positive value in both HTA2.0 and qRT-PCR analyses. However, the SI value in AA samples (qRT-PCR) is lower compared to $\mathrm{CA}$. This relates to the overall gene signal being higher in $\mathrm{HCV}+$ cirrhotic liver (Table 5A, upper), thus more sliced out (higher signal) compared to normal. These data suggest that the observed disparity in $\mathrm{HCV}$-induced HCC seen in CA and AA tissue samples could be due, in part, to transcriptome diversity of specific genes like $S A A 1$, PCNA-AS1, IFI30, DBA2, and ROBO1.

\section{Hepatocyte nuclear factor $4 \alpha(\mathrm{HNF} 4 \alpha)$ and serum amyloid A1 (SAA1)-associated protein staining patterns in liver and tumor tissue samples}

Since $S A A 1$ is transcriptionally regulated by $H N F 4 \alpha$ [26], we examined the staining patterns of both 
Table 3: The results of alternative splicing (AS) events in Normal vs. HCV+ tissue samples using Affymetrix Human Transcriptomic Array 2.0 (HTA 2.0)

\begin{tabular}{|c|c|c|c|c|c|}
\hline $\begin{array}{l}\text { Accession } \\
\text { Number }\end{array}$ & $\begin{array}{c}\text { Fold Change } \\
\text { (FC) }\end{array}$ & Gene Symbol & Group & Splicing Index (SI)* & Splicing Events \\
\hline NM_005950 & 10.24 & MT1G & Coding & -2.14 & Cassette Exon \\
\hline NM_176870 & 9.94 & MT1M & Coding & -2.37 & Cassette Exon \\
\hline NM_005949 & 7.44 & MT1F & Coding & -2.84 & \\
\hline NM_017460 & 6.68 & CYP3A4 & Coding & 3.18 & \\
\hline NM_017460 & 6.68 & CYP3A4 & Coding & 2.19 & \\
\hline NM_017460 & 6.68 & CYP3A4 & Coding & -2.03 & \\
\hline NM_017460 & 6.68 & CYP3A4 & Coding & -2.22 & Cassette Exon \\
\hline NM_017460 & 6.68 & CYP3A4 & Coding & -4.27 & Alternative 5' Donor Site \\
\hline NM_017460 & 6.68 & CYP3A4 & Coding & -4.36 & \\
\hline NM_030787 & 6.44 & CFHR5 & Coding & 2.03 & \\
\hline NM_000669 & 5.58 & ADH1C & Coding & 2.08 & Alternative $5^{\prime}$ Donor Site \\
\hline NM_000669 & 5.58 & $\mathrm{ADH} 1 \mathrm{C}$ & Coding & -4.86 & Cassette Exon \\
\hline NM_001881 & 4.81 & CRHBP & Coding & 2.15 & Alternative 5' Donor Site \\
\hline NM_001881 & 4.81 & CRHBP & Coding & -4.8 & Cassette Exon \\
\hline NM_019844 & 4.74 & SLCO1B3 & Coding & -2.3 & Cassette Exon \\
\hline NM_019844 & 4.74 & SLCO1B3 & Coding & -2.31 & \\
\hline NM_019844 & 4.74 & SLCO1B3 & Coding & -2.36 & Cassette Exon \\
\hline NM_019844 & 4.74 & SLCO1B3 & Coding & -2.46 & \\
\hline NM_019844 & 4.74 & SLCO1B3 & Coding & -2.76 & Alternative $3^{\prime}$ Acceptor Site \\
\hline NM_019844 & 4.74 & SLCO1B3 & Coding & -3.72 & Cassette Exon \\
\hline NM_019844 & 4.74 & SLCO1B3 & Coding & -4.19 & Cassette Exon \\
\hline NM_019844 & 4.74 & SLCO1B3 & Coding & -4.4 & Cassette Exon \\
\hline NM_019844 & 4.74 & SLCO1B3 & Coding & -4.84 & \\
\hline NM_003708 & 4.49 & RDH16 & Coding & -3.3 & Alternative 5' Donor Site \\
\hline NM_177550 & 4.47 & SLC13A5 & Coding & 2.66 & \\
\hline NM_177550 & 4.47 & SLC13A5 & Coding & -2.54 & \\
\hline NM_177550 & 4.47 & SLC13A5 & Coding & -5.52 & Alternative $3^{\prime}$ Acceptor Site \\
\hline NM_003645 & 4.42 & SLC27A2 & Coding & -3.63 & \\
\hline NM_001308 & 4.37 & CPN1 & Coding & -2.86 & Alternative $3^{\prime}$ Acceptor Site \\
\hline NM_006100 & 4.36 & ST3GAL6 & Coding & 2.41 & \\
\hline NM_006100 & 4.36 & ST3GAL6 & Coding & -2.1 & Cassette Exon \\
\hline NM_006100 & 4.36 & ST3GAL6 & Coding & -2.19 & Cassette Exon \\
\hline NM_006100 & 4.36 & ST3GAL6 & Coding & -2.21 & Cassette Exon \\
\hline NM_006100 & 4.36 & ST3GAL6 & Coding & -2.66 & Cassette Exon \\
\hline NM_006100 & 4.36 & ST3GAL6 & Coding & -2.8 & Cassette Exon \\
\hline
\end{tabular}

(Continued) 


\begin{tabular}{|c|c|c|c|c|c|}
\hline $\begin{array}{l}\text { Accession } \\
\text { Number }\end{array}$ & $\begin{array}{l}\text { Fold Change } \\
\text { (FC) }\end{array}$ & Gene Symbol & Group & Splicing Index (SI)* & Splicing Events \\
\hline NM_006100 & 4.36 & ST3GAL6 & Coding & -3.23 & \\
\hline NM_006100 & 4.36 & ST3GAL6 & Coding & -3.57 & Alternative 5 ' Donor Site \\
\hline NM_006100 & 4.36 & ST3GAL6 & Coding & -3.81 & Cassette Exon \\
\hline NM_006100 & 4.36 & ST3GAL6 & Coding & -6.23 & Alternative 3' Acceptor Site \\
\hline NM_004944 & 4.33 & DNASE1L3 & Coding & -3.74 & Intron Retention \\
\hline NM_004944 & 4.33 & DNASE1L3 & Coding & -5.49 & Alternative 5' Donor Site \\
\hline NM_004944 & 4.33 & DNASE1L3 & Coding & -6.67 & \\
\hline NM_018388 & 4.22 & MBNL3 & Coding & -2.13 & \\
\hline NM_018388 & 4.22 & MBNL3 & Coding & -4.34 & Cassette Exon \\
\hline NM_012068 & 3.8 & ATF5 & Coding & -2.2 & Alternative 5' Donor Site \\
\hline NM_012068 & 3.8 & ATF5 & Coding & -3.13 & Cassette Exon \\
\hline NM_012068 & 3.8 & ATF5 & Coding & -3.2 & \\
\hline NM_030754 & 3.69 & SAA2 & Coding & 22.12 & \\
\hline NM_030754 & 3.69 & SAA2 & Coding & 12.96 & \\
\hline NM_030754 & 3.69 & SAA2 & Coding & 10.89 & \\
\hline NM_030754 & 3.69 & SAA2 & Coding & 8.47 & \\
\hline NM_030754 & 3.69 & SAA2 & Coding & 8.4 & Intron Retention \\
\hline NM_030754 & 3.69 & SAA2 & Coding & 6.78 & Cassette Exon \\
\hline NM_030754 & 3.69 & SAA2 & Coding & 5.96 & \\
\hline NM_030754 & 3.69 & SAA2 & Coding & 5.25 & Cassette Exon \\
\hline NM_030754 & 3.69 & SAA2 & Coding & 5.11 & Cassette Exon \\
\hline NM_030754 & 3.69 & SAA2 & Coding & 5.01 & \\
\hline NM_030754 & 3.69 & SAA2 & Coding & 3.97 & Cassette Exon \\
\hline NM_030754 & 3.69 & SAA2 & Coding & 2.52 & \\
\hline NM_030754 & 3.69 & SAA2 & Coding & -2.63 & Alternative 5' Donor Site \\
\hline NM_024039 & 3.65 & MIS12 & Coding & -2.1 & Cassette Exon \\
\hline NM_024039 & 3.65 & MIS12 & Coding & -2.79 & \\
\hline NM_024039 & 3.65 & MIS12 & Coding & -3.67 & Alternative 5' Donor Site \\
\hline NM_005952 & 3.65 & MT1X & Coding & -10.33 & Alternative 3' Acceptor Site \\
\hline NM_005952 & 3.61 & MT1X & Coding & -3.98 & Cassette Exon \\
\hline NM_005952 & 3.6 & MT1X & Coding & -4.2 & \\
\hline NM_005952 & 3.59 & MT1X & Coding & -2.23 & Cassette Exon \\
\hline NM_024331 & 3.59 & TTPAL & Coding & -2.96 & \\
\hline NM_001361 & 3.54 & DHODH & Coding & -2.03 & \\
\hline NM_000236 & 3.54 & LIPC & Coding & -4.04 & Alternative 5' Donor Site \\
\hline NM_000236 & 3.48 & LIPC & Coding & -2.27 & Cassette Exon \\
\hline NM_031900 & 3.48 & AGXT2 & Coding & -4.04 & \\
\hline
\end{tabular}

(Continued) 


\begin{tabular}{|c|c|c|c|c|c|}
\hline $\begin{array}{l}\text { Accession } \\
\text { Number }\end{array}$ & $\begin{array}{c}\text { Fold Change } \\
\text { (FC) }\end{array}$ & Gene Symbol & Group & Splicing Index (SI)* & Splicing Events \\
\hline NM_052972 & 3.41 & LRG1 & Coding & -3.18 & Alternative 5' Donor Site \\
\hline NM_032565 & 3.39 & EBPL & Coding & -2.06 & \\
\hline NM_032565 & 3.39 & EBPL & Coding & -2.11 & Cassette Exon \\
\hline NM_024641 & 3.39 & MANEA & Coding & -2.2 & Cassette Exon \\
\hline NM_020988 & 3.39 & GNAO1 & Coding & -2.2 & Cassette Exon \\
\hline NM_020988 & 3.39 & GNAO1 & Coding & -2.97 & Cassette Exon \\
\hline NM_020988 & 3.37 & GNAO1 & Coding & -3.68 & \\
\hline NM_020988 & 3.37 & GNAO1 & Coding & -2.04 & Cassette Exon \\
\hline NM_020988 & 3.37 & GNAO1 & Coding & -2.19 & \\
\hline NM_020988 & 3.37 & GNAO1 & Coding & -2.46 & \\
\hline NM_000028 & 3.37 & AGL & Coding & -2.74 & Cassette Exon \\
\hline NM_000028 & 3.36 & AGL & Coding & -2.96 & \\
\hline NM_000028 & 3.36 & AGL & Coding & 26.12 & \\
\hline NM_000028 & 3.36 & AGL & Coding & 12.96 & \\
\hline NM_000028 & 3.36 & AGL & Coding & 8.08 & Intron Retention \\
\hline NM_000331 & 3.36 & SAA1 & Coding & 4.49 & \\
\hline NM_000331 & 3.27 & SAA1 & Coding & 2.21 & \\
\hline NM_000331 & 3.27 & SAA1 & Coding & -2.05 & Cassette Exon \\
\hline NM_000331 & 3.27 & SAA1 & Coding & -2.66 & Alternative 5' Donor Site \\
\hline NM_000331 & 3.27 & SAA1 & Coding & -3.06 & Alternative 3' Acceptor Site \\
\hline NM_001159 & 3.27 & AOX1 & Coding & -3.42 & \\
\hline NM_015506 & 3.27 & MMACHC & Coding & -3.86 & Alternative 5' Donor Site \\
\hline
\end{tabular}

Results were obtained following data normalization using Affymetrix Transcriptome Analysis Console 2.0 (TAC 2.0) software, which determines the Splicing Index (SI) of a gene and $q$-value $<0.05 \mathrm{FC}$ as criteria for selection.

$* \mathrm{SI}=$ The ratio of the exon intensities in Normal vs. HCV+ livers after normalization to their respective gene intensities in each sample. $\mathrm{SI}=(0)$ value indicates that the Probeset Selection Region (PSR) is present at equal levels in both Normal and $\mathrm{HCV}+$ livers. $\mathrm{SI}=(+)$ value implies elevated inclusion, and $(-)$ value suggests increased PSR skipping in Normal vs. HCV+ livers.

proteins in 72 tissues sections for CA and AA using immunohistochemical analysis (Figures 2 and 3). Intense staining for SAA1 and P1/P2-HNF4 $\alpha$ was observed in normal liver tissues for both $\mathrm{CA}$ (Figure 2Aa, and 2Ad) and $\mathrm{AA}(2 \mathrm{Ba}$, and $2 \mathrm{Bd})$. In contrast, the staining reactivity for both proteins showed a tendency to decrease in $\mathrm{HCV}+$ cirrhotic livers of AA (Figure 2Bb, and 2Be) compared to $\mathrm{CA}(2 \mathrm{Ab}$, and 2Ae). As shown in Figure 2C and 2D, the percentage of reactivity for SAA1 and $\mathrm{P} 1 / \mathrm{P} 2-\mathrm{HNF} 4 \alpha$ are 6.5 and 40 in AA, whereas in CA they are 25 and 50 , respectively. Likewise, the staining patterns for both SAA1 and P1/P2-HNF4 $\alpha$ in HCC are different in AA compared to CA samples. In AA tumor samples, there was no staining detected for SAA1 (Figure 2Bc), whereas intense staining was detected for P1/P2-HNF4 $\alpha$ (Figure
2Bf). For CA tumor samples, staining was detected for both proteins, although less than what is detected in normal tissues (Figure 2Ac, and 2Af). Figure 3A illustrates the staining pattern of $\mathrm{P} 1-\mathrm{HNF} 4 \alpha$ in tissue samples for both $\mathrm{CA}$ and $\mathrm{AA}$. In $\mathrm{HCV}+$ tissues, the percentage reactivity of $\mathrm{P} 1-\mathrm{HNF} 4 \alpha$ is higher in $\mathrm{CA}(125 \%)$, and lower in $\mathrm{AA}(50 \%)$. There is no clear difference in $\mathrm{HCC}$ staining reactivity of $\mathrm{P} 1-\mathrm{HNF} 4 \alpha$ between $\mathrm{CA}$ and AA.

\section{DISCUSSION}

We previously showed [12] that there are distinct alterations in the expression of transcripts and proteins exist in CA liver and tumor tissue samples based on $\mathrm{HCV}$ disease state. However, the levels of expression 
Table 4A: Functional analysis of 636 differentially expressed genes (DEGs) between Normal vs. HCV+ tissue samples

Top Canonical Pathways

\begin{tabular}{lcc}
\hline Name & p-value & ratio \\
Hepatic Fibrosis/Hepatic Stellate Cell Activation & $4.25 \mathrm{E}-04$ & $28 / 127(0.22)$ \\
Antigen Presentation Pathway & $4.34 \mathrm{E}-04$ & $8 / 18(0.44)$ \\
Graft-versus-Host Disease Signaling & $1.48 \mathrm{E}-03$ & $8 / 21(0.381)$ \\
Inhibition of Matrix Metalloproteases & $2.89 \mathrm{E}-03$ & $8 / 23(0.348)$ \\
T Helper Cell Differentiation & $3.37 \mathrm{E}-03$ & $11 / 39(0.282)$ \\
Top Toxicity Functions & & \#-value \\
Name & $4.96 \mathrm{E}-03-4.96 \mathrm{E}-03$ & 5 \\
Liver Cirrhosis & $1.01 \mathrm{E}-01-1.01 \mathrm{E}-01$ & 4 \\
Liver Necrosis/Cell Death & $1.14 \mathrm{E}-01-1.14 \mathrm{E}-01$ & 1 \\
Liver Adhesion & $2.16 \mathrm{E}-01-6.22 \mathrm{E}-01$ & 3 \\
Liver Fibrosis & $2.16 \mathrm{E}-01-6.22 \mathrm{E}-01$ & 3 \\
Liver Proliferation & & $\boldsymbol{2}$ \\
Molecular and Cellular Functions & & 3 \\
Name & & $3.29 \mathrm{E}-02-2.29 \mathrm{E}-02$ \\
DNA Replication, Recombination, and Repair & & Molecules \\
\hline
\end{tabular}

Table 4B: Functional analysis of 61 differentially expressed genes (DEGs) between HCCN vs. HCC tissue samples

Top Canonical Pathways

Name

GADD45 Signaling

Cell Cycle Control of Chromosomal Replication

Estrogen-mediated S-Phase Entry

Cell Cycle: G2/M DNA Damage Checkpoint Regulation

Cyclins and Cell Cycle Regulation

\section{Top Toxicity Functions}

Name

Hepatocellular Carcinoma

Liver Hyperplasia/Hyperproliferation

Glutathione Depletion in Liver

Liver Damage

Liver Degradation

\section{Molecular and Cellular Functions}

Name

Carbohydrate Metabolism

Drug Metabolism

Molecular Transport

Small Molecule Biochemistry

Post-Translational Modification

\section{p-value}

2.93E-06

$1.07 \mathrm{E}-05$

2.24E-05

2.31E-05

6.44E-05

p-value

3.50E-03-5.87E-01

$3.50 \mathrm{E}-03-5.87 \mathrm{E}-01$

5.37E-02-5.38E-01

5.37E-02 - 3.92E-01

5.37E-02 - 5.37E-02

p-value

$1.42 \mathrm{E}-03-1.42 \mathrm{E}-03$

$1.42 \mathrm{E}-03-1.42 \mathrm{E}-03$

1.42E-03 - 3.73E-02

1.42E-03 - 3.73E-02

$2.88 \mathrm{E}-03-2.88 \mathrm{E}-03$ ratio

$8 / 19(0.421)$

$8 / 22(0.364)$

$8 / 24(0.333)$

$11 / 46(0.239)$

$13 / 69(0.188)$

\# Molecules

9

31

2

7

1

\# Molecules

3

3

7

10 
Table 5A: qRT-PCR validation of 8 selected DEGs

\begin{tabular}{|c|c|c|c|c|c|c|}
\hline \multirow{3}{*}{$\begin{array}{l}\text { Disease Stage } \\
\text { Normal vs. HCV+ }\end{array}$} & \multirow{3}{*}{ Gene Symbol } & \multirow{3}{*}{ Accession Number } & \multicolumn{4}{|c|}{ Fold Change (FC) } \\
\hline & & & \multicolumn{2}{|c|}{ HTA 2.0} & \multicolumn{2}{|c|}{ qRT-PCR } \\
\hline & & & $\mathrm{CA}$ & AA & $\mathrm{CA}$ & AA \\
\hline & $S A A 1$ & NM_000331 & 3.36 & NA & 3.12 & $2.0^{*}$ \\
\hline & $A O X 1$ & NM_001159 & 3.45 & NA & 3.10 & 3.3 \\
\hline & SLC13A5 & NM_001143838 & 3.27 & NA & 3.51 & 3.0 \\
\hline \multirow[t]{5}{*}{$\mathrm{HCCN}$ vs. $\mathrm{HCV}+\mathrm{HCC}$} & $P C N A-A S 1$ & NR_028370 & 3.53 & NA & 3.2 & $0.99 *$ \\
\hline & $R O B O 1$ & NM_001145845 & 2.20 & NA & 2.9 & $0.20 *$ \\
\hline & $D A B 2$ & NM_001244871 & 2.20 & NA & 3.0 & $0.55^{*}$ \\
\hline & $\operatorname{IFI30}$ & NM_001244871 & 2.21 & NA & 2.0 & $0.72 *$ \\
\hline & SNORD82 & NR_004398 & -2.20 & NA & -2.0 & -2.0 \\
\hline
\end{tabular}

CA: Caucasian American; AA: African American.

$* p<0.05$; mean average of 3 biological replicates from each cohort.

Table 5B: qRT-PCR validation of alternative splicing of 3 selected genes

\begin{tabular}{|c|c|c|c|c|c|c|}
\hline \multirow{3}{*}{$\begin{array}{l}\text { Disease Stage } \\
\text { Normal vs. HCV+ }\end{array}$} & \multirow[t]{3}{*}{ Gene Symbol } & \multirow[t]{3}{*}{ Accession Number } & \multicolumn{4}{|c|}{ Splicing Index (SI) } \\
\hline & & & \multicolumn{2}{|c|}{ HTA 2.0} & \multicolumn{2}{|c|}{ qRT-PCR } \\
\hline & & & $\mathrm{CA}$ & $\mathrm{AA}$ & $\mathrm{CA}$ & $\mathrm{AA}$ \\
\hline & $S A A 1$ & NM_000331 & 10.77 & NA & 9.12 & $3.21^{*}$ \\
\hline & $A O X 1$ & NM_001159 & -2.55 & NA & -2.10 & -1.38 \\
\hline & $S L C 13 A 5$ & NM_001143838 & -1.37 & NA & -1.61 & -1.12 \\
\hline
\end{tabular}

CA: Caucasian American; AA: African American.

$* p<0.05$; mean average of 3 biological replicates from each cohort.

were different when the results were cross- validated on tissue samples of AA cohort. The aim of the current study was to follow up on these findings and investigate, at the whole transcriptome level, the extent to which splice variant events may play a role in this genomic diversity of HCV disease state and racial disparity. Alternative splicing of mRNA is a major mechanism that generates diverse mRNA transcript isoforms from a single gene, and subsequently differentiates proteins to have varying cellular processes [19-23]. These variants are targeted as biomarkers in disease diagnosis, prognosis and treatment [27-29].

In the present study, genome-wide analyses of genes and alternative splicing events of human liver and tumor tissues were performed using the newly developed Affymetrix Human Transcriptome 2.0 arrays (HTA 2.0). With a high density of oligonucleotide probes, these arrays cover the exonic regions of human genome as well as junction regions between adjacent exons. Many changes were apparent in $\mathrm{HCV}+$ cirrhotic $v s$. normal livers, even more so than HCV+HCC vs. HCCN. This may indicate that $\mathrm{HCV}+$ cirrhotic livers, as a type of intermediary lesion in $\mathrm{HCV}$ disease progression, already exhibited strong signs of alternations. From the molecular changes evidenced in $\mathrm{HCV}+($ Figure 1A), it is clear that $\mathrm{HCV}+$ cirrhotic livers are not merely accumulating alterations that will be found in $\mathrm{HCV}+\mathrm{HCC}$ (Figure 1B). Possibly, the evolution to HCC follows a more strictly clonal expansion, which may select for gene changes important for clonal growth while eliminating less relevant modifications. According to this hypothesis, $\mathrm{HCV}+$ cirrhotic livers may have different outcomes, some evolving toward cancer (HCC), whereas others could be prone to disappearance. In this case, we were able to identify more genes expressed in normal $v s$. $\mathrm{HCV}+(636$ DEGs), whereas only 61 DEGs were detected in $\mathrm{HCCN}$ vs. $\mathrm{HCV}+\mathrm{HCC}$. No overlap of genes was detected between the two disease states.

Tables 1A \& 1B show specific gene expression alterations in normal vs. $\mathrm{HCV}+$. The signature of 350 probes corresponding to downregulated genes in $\mathrm{HCV}+$ compared to normal is shown in Table 1A. Among the highest down- regulated genes are: $A V R 1 A, S A A 2, M T 1 F$, CFHR5, SLITRK3, CLEC4M, SAA1, CPN1, TIMD4, $G P R 125$, and $A O X 1$. Most of these genes have not been 
described to be associated with $\mathrm{HCV}+$ cirrhotic livers, although several of the changes agreed to previous reports including variations in the expression levels of $S A A 1$, $S A A 2$ or $M T 1 F$ [30-33]. For example, SAA1 and SAA2 are well-known acute phase reactants, and their serum levels were shown to be down regulated in $\mathrm{HBV}$-associated HCC patients compared to healthy individuals [34]. In our study, both $S A A 1$ and $S A A 2$ are down regulated in $\mathrm{HCV}+$ liver compared to normal (Figure 1A). As tumor suppressor, metallothionein $1 \mathrm{~F}(M T 1 F)$ has been shown to be down regulated in several tumors as part of cancer initiation and/or progression [35]. The signature of 286 probes corresponding to upregulated genes in $\mathrm{HCV}+$ compared to normal is shown in Table 1B. Among the highest upregulated genes are: AKR1B10, IFI27, IL8, VTRNA1-1, SPP1, GDF15, CXCL10, IGLC7, and LGALS4. The expression of these genes is known to be strongly associated with $\mathrm{HCV}$-induced liver cirrhosis and/ or HCC [36-45]. In Figure 1A, both SPP1 and IL8 are upregulated in $\mathrm{HCV}+$ cirrhotic liver compared to normal.

The signature of 61 probes corresponding to genes showing expression alterations in $\mathrm{HCCN} v s . \mathrm{HCV}+\mathrm{HCC}$ is shown in Table 2. In this disease state, 47 genes (77\%) are upregulated, whereas 14 genes $(23 \%)$ are downregulated. Among the top deregulated probes, $P C N A-A S 1$ has been found to be the most up-regulated probes in $\mathrm{HCV}+\mathrm{HCC}$ compared to HCCN, whereas SNORD82, among the downregulated probes (Figure 1B). Both genes are considered long non-coding RNAs (lncRNAs) and well recognized to play major regulatory roles in disease development. For example, PCNA-AS1 was shown to act as an upstream regulator in HCC [46], and SNORD82 has been found to be involved in the development of prostate and breast cancers [47, 48]. Ingenuity Pathway Analysis (IPA) was performed using Ingenuity software, as we reported previously [12] to understand the correlation between the canonical biological pathways and the deregulated genes identified in this study. Among the top 5 canonical pathways for normal vs. $\mathrm{HCV}+$ state (Table 5A) was Hepatic Fibrosis/Satellite Cell Activation ( $p=4.25 \mathrm{E}-04)$. In hepatic fibrosis, hepatotoxins like HCV initiate a cascade of stress related pro-inflammatory events, which eventually activate Hepatic Stellate cells (HSCs). Activated HSCs secrete cytokines that perpetuate their activated state. Continued liver injury results in an accumulation of activated HSCs, which in turn synthesize
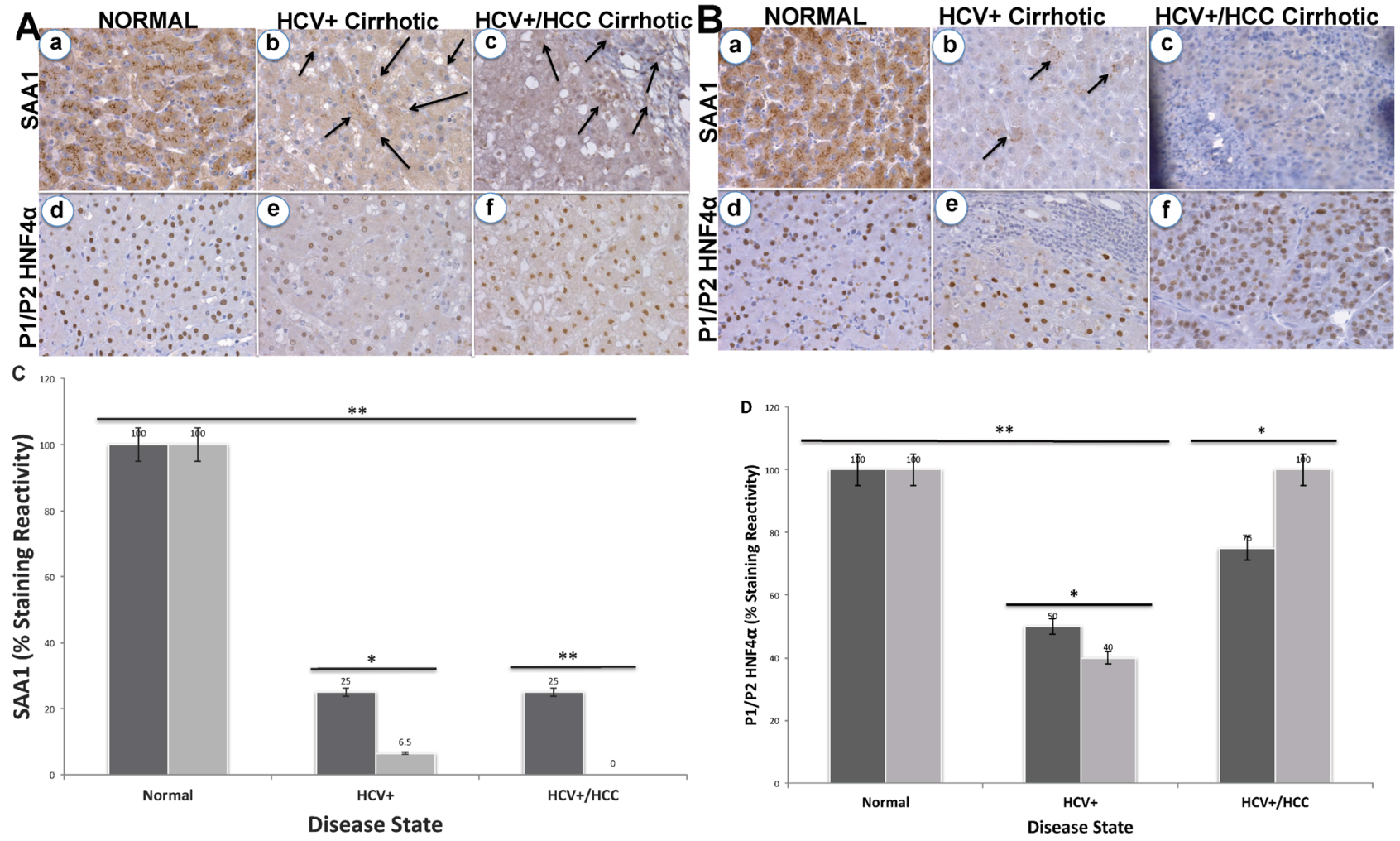

Figure 2: Immunohistochemical staining of SAA1 and P1/P2-HNF4a. (A) Normal (a and d, respectively), HCV+ cirrhotic (b and e, respectively), and $\mathrm{HCV}+/ \mathrm{HCC}$ cirrhotic (c and f, respectively) in CA. (B) Normal (a and d, respectively), HCV + cirrhotic (b and e, respectively), and $\mathrm{HCV}+/ \mathrm{HCC}$ cirrhotic (c and f, respectively) in AA. Bar graphs $=\%$ staining reactivity (Y-axis) $v s$. disease state (X-axis) for SAA1 (C) and P1/P2-HNF4 $\alpha$ (D). Black bar $=\mathrm{CA}$; Gray bar $=\mathrm{AA}(n=3-4$ tissue sections from 24 paraffin embedded tissue blocks \pm S.E; $\left.{ }^{*} p<0.05 ; * * p<0.001\right)$. 
large amount of extracellular matrix (ECM) proteins, leading to severe fibrosis and eventually liver cirrhosis. $S A A 1$ and $S A A 2$ genes are among the molecules activated in this disease state (acute phase reactants), and both are down regulated indicating a possible involvement in disease initiation to $\mathrm{HCC}$. For $\mathrm{HCCN}$ vs. $\mathrm{HCV}+\mathrm{HCC}$ state (Table 5B), GADD45 Signaling was the top pathway identified ( $p=2.93 \mathrm{E}-06)$. It has been implicated in stress signaling response that can result in cell cycle arrest, DNA repair, cell survival, senescence, and apoptosis. This response is mediated via a complex binding to several proteins involved in these processes, including PCNA and thus PCNA-ASI was found to be upregulated in HCC (Figure 1B).

We next validated the expression of 8 DEGs by real-time qRT-PCR using independent samples for CA and AA, as shown in Table 5A. Although it is clearly shown in this table that there is good concordance in results obtained using both platforms, the level of $S A A 1$ in AA samples (normal vs. $\mathrm{HCV}+$ state) is significantly lower than that of CA $(p<0.05)$. Thus, immune response to chronic $\mathrm{HCV}$ infection may play a crucial role in $\mathrm{HCV}$ racial disparities. Four ( $P C N A-A S 1, R O B O 1, D A B 2$ and $I F I 30$ ) out 5 transcripts with increased expression in $\mathrm{HCCN}$ vs. $\mathrm{HCV}+\mathrm{HCC}$ state (Table 2) were found to be significantly lower $(p<0.05)$ in AA compared to CA samples. Thus, in addition to the immune responseassociated genes, these genes could also play a role in $\mathrm{HCV} / \mathrm{HCC}$ racial disparities seen between $\mathrm{CA}$ and AA samples, and might be valuable markers for early diagnosis of the disease based on racial background of patients.

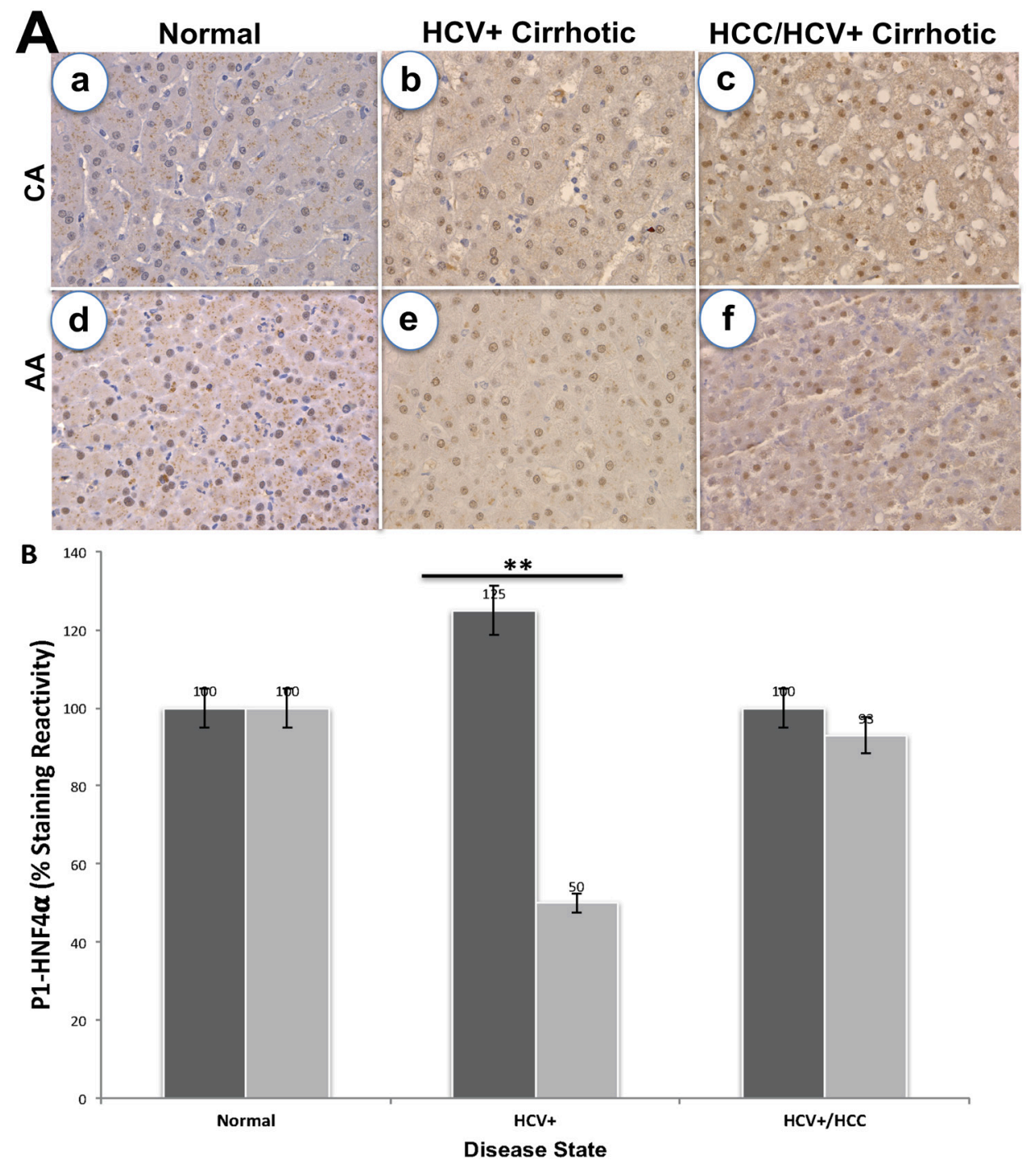

Figure 3: Immunohistochemical staining of P1-HNF4a. (A) Staining in normal, HCV+ and HCC for CA (a-c) and AA (d-f) tissue samples. (B) Bar graphs $=\%$ staining reactivity (Y-axis) $v s$. disease state (X-axis) for CA, black bar and AA, grey bar $(n=3-4$ tissue sections from 24 paraffin embedded tissue blocks \pm S.E; $* p<0.05 ; * *<0.001)$. 
Since SAAl (acute response reactant) is transcriptionally regulated by $H N F 4 \alpha$ [49] we validated the expression of both using immunohistochemical analysis. $H N F 4 \alpha$ is a member of the superfamily of liganddependent transcription factors (TFs) and master regulator of tissue-specific gene expression in the liver [50]. It inhibits progression of HCC in mice [17, 18]. There are two alternative promoters that drive expression of $H N F 4 \alpha$ gene (P1 and $\mathrm{P} 2$ ) and give rise to HNF4 $\alpha$ isoforms that differ by $16-38$ amino acids in their terminal region [51]. While the different isoforms have identical DNA and ligand binding domains, there subtle yet significant functional differences between the HNF $4 \alpha$ isoforms. Both P1- and P2-driven $H N F 4 \alpha$ are expressed in the fetal liver but only $\mathrm{P} 1-H N F 4 \alpha$ is expressed in the normal adult liver [52], and $\mathrm{P} 1-H N F 4 \alpha$ is down regulated in human HCC while P2- HNF4 $\alpha$ is upregulated [51]. Furthermore, $\mathrm{P} 1-H N F 4 \alpha$ is known to repress the activation of the $\mathrm{P} 2$ promoter [51], which could explain the switch between the two isoforms. In this study, we used both H1415 and K9218 monoclonal antibodies to detect P1/P2- and P1-promoter-driven $H N F 4 \alpha$, respectively, in the liver and tumor samples to determine how the expression of these two isoforms may play a role in SAA1 expression patterns. Our data in Figure 2 clearly indicate that staining reactivity of SAA1 and $\mathrm{P} 1 / \mathrm{P} 2-\mathrm{HNF} 4 \alpha$ is altered based on HCV disease state and race. For example, staining reactivity (\%) for SAA1 (Figure 2C) in CA is $25 \%$ for both $\mathrm{HCV}+$ cirrhotic and $\mathrm{HCC}$ states, whereas in AA samples it is only $6.5 \%$ and $0.0 \%$, respectively. This indicate that the marker for "acute inflammatory phase" is much lower in $\mathrm{HCV}+$ of AA compared to CA cohort. As shown in Figure $2 \mathrm{D}$, the staining reactivity of $\mathrm{P} 1 / \mathrm{P} 2-H N F 4 \alpha$, which is a measure of both isoforms, is lower in $\mathrm{HCV}+$ for both $\mathrm{CA}$ and AA tissue samples. However, it is clearly shown in Figure $3 \mathrm{~B}$ that the low staining reactivity is related to $\mathrm{P} 1-$ $H N F 4 \alpha$ isoform, and mainly in AA tissue samples. These data clearly indicate that the acute inflammatory phase as measured by SAA1 level is severely compromised in AA compared to CA as a result of dysregulation of $H N F 4 \alpha$ isoforms. Our results also show that changes in splicing profiles in normal $v s$. $\mathrm{HCV}+$ state could possibly contribute to the observed HCV disease state racial disparity (Table 3 ). The alternative splicing events of three genes (SAA1, AOX1 and SLC13A5) from the 28-gene set (Table 3 ) were confirmed by real-time qRT-PCR in normal $v s$. HCV+ state. Specifically, we validated the expression of $S A A 1, A O X 1$, and $S L C 13 A 5$. For $S A A 1$, the expression of exon 1 to 2 and exon 1 to 3 (Supplementary Figure 1), for $A O X 14$ to 5, and the exon 12 to 13, for $S L C 13 A 5$ exon 10 to 12 (Supplementary Figure 2). We found that the splicing index (SI) of $S A A 1$ is significantly lower $(p<0.05)$ in AA compared to CA (Table 5B). This suggests that splicing events occurred mainly in specific disease state $(\mathrm{HCV}+$ cirrhotic) predominantly in AA cohort. The role played by these alternative splice products in $\mathrm{HCV}+$ will thus require further investigations, together with the other alternative transcripts detected. In sum, our study suggests that altered gene expression, and splice variants are important events in HCV racial disparities between Caucasian and African Americans.

In conclusion, our genomic variants study showed that genes were differentially expressed between HCCN and $\mathrm{HCV}+\mathrm{HCC}$ but, also, to a large extent, between normal and $\mathrm{HCV}+$ (cirrhotic) state. Many of these genes are involved in biological pathways pertinent to the overall pathophysiological response to $\mathrm{HCV}$ infection. The observation that several splice variants were deregulated in normal vs. HCV+ is certainly in line with the recent observations showing that the pre-mRNA splicing machinery may be profoundly remodeled during $\mathrm{HCV}$ disease progression, and may, therefore, play a major role in the disease outcome. Target validation analyses showed that some of these genes are significantly deregulated especially in AA compared to CA tissue samples. These observations suggest that socioeconomic factors may not fully explain the differences in HCV racial disparity, but rather biological/genetic factors should also be considered. Further analyses will be required to determine if these gene variants are predictive markers of the pathophysiological evolution in $\mathrm{HCV}$ disease progression. It would be of great interest to determine whether our differentially expressed genes and splice variants are under some kind of coordinated control. This certainly will allow for the development of next generation therapeutic care management for $\mathrm{HCV}$ disease state based on racial/ethnic backgrounds of patients.

\section{MATERIALS AND METHODS}

\section{Sample preparation and data analysis}

Total RNA was extracted from 12 tissue samples of Caucasian individuals (3 normal livers, $3 \mathrm{HCV}+/$ HCC- (cirrhotic livers), $3 \mathrm{HCV}+\mathrm{HCC}+$ (cirrhotic tumors) and 3 normal adjacent tissue matched pairs HCCN) using the RNeasy mini kit (Qiagen, Valencia, CA, USA) and quantified using Nanodrop ND-100 Spectrophotometer (Thermo Fisher Scientific, Waltham, MA, USA), as previously reported [12]. RNA samples were then subjected to RNA amplification using the SensationPlus FFPE Amplification and WT Labeling Kit (Affymetrix Inc., Santa Clara, CA, USA), as previously reported [53, 54]. The biotin double-stranded cDNA products were hybridized to Affymetrix HTA 2.0 arrays using an Affymetrix hybridization kit. Hybridized HTA 2.0 arrays were scanned with an Affymetrix GeneChip ${ }^{\circledR}$ 3000 fluorescent scanner. Image generation and feature extraction was performed using Affymetrix GeneChip Command Console Software. The raw data (.*CEL) were analyzed using the Transcriptome Analysis Console (TAC) 2.0 software, which allows for the identification 
of differentially expressed genes (DEG) \& exons and the visualization of alternative splicing events for determining possible transcript isoforms that may exist in samples.

For microarray data analysis, two parallel analyses (gene-level and alternative splicing level) were performed. Data were normalized using quantile normalization, and background noise was detected using Detection Above Background (DABG) algorithm. Only the probesets characterized by a DABG $p$-value $<0.05$ in at least $50 \%$ of the samples were considered for statistical analysis. We performed an unpaired Student's $t$-test to compare gene intensities between normal vs. $\mathrm{HCV}+$ and $\mathrm{HCCN}$ vs. $\mathrm{HCV}+\mathrm{HCC}$. Genes were considered significantly regulated when Fold Change (FC), linear $<-2.0$ or $>+2.0$ and ANOVA $p$-value (condition pair) $<0.05$. Analysis of the splicing level was also performed using TAC 2.0 software, which determines among other parameters, the Splicing Index (SI) of a gene. The SI corresponds to a comparison of gene-normalized exon-intensity values between the two analyzed experimental conditions [55]. Additional criteria used beside SI: $q$-value $<0.05$, a gene is expressed in both conditions (normal vs. $\mathrm{HCV}+$, and $\mathrm{HCCN}$ vs. HCV+HCC), a Probset Ratio (PSR)/Junction must be expressed in at least one condition, and a gene must contain at least one PSR value.

\section{Reverse transcription PCR validation}

Validation of 8 selected differentially expressed genes (DEGs) and splice variants was performed on 24 independent tissue samples (12 CA, and $12 \mathrm{AA}$ ) at various disease state (normal, $\mathrm{HCV}+$ and $\mathrm{HCC}$ ). mRNA levels were measured using the SYBR-GREEN quantitative RT-PCR (qRT-PCR) method as previously reported [12] by the ABI 7900HT Fast Real Time PCR System (Applied Biosystems). cDNAs were amplified using specific primers indicated in Supplementary Table 1; data results were normalized against alphaACTIN (ACTIN1), beta-2-Microglobin (B2M), and glyceraldehyde 3-phosphate dehydrogenase (GAPDH). Relative RNA levels of genes were calculated using the comparative $\mathrm{Ct}$ method $2^{-\Delta \Delta \mathrm{Ct}}[56]$. For splice variants, altspliced (A) and constitutive (C) exons were identified in TAC 2.0, and qRT-PCR primer sets were designed using Primer3 (http://www.ncbi.nlm.nih.gov/tools/primerblast/) as shown in Supplementary Table 1. By designing specific primer pairs for constitutively expressed flanking exons (Supplementary Figure 1 and 2), it is possible to simultaneously amplify isoforms that include or skip the target exon [57]. The identities of variant specific amplicons were simultaneously verified and quantitated by melt curve analysis, and the products were confirmed either present or absent using agarose gel electrophoresis. Splice Index (SI) was calculated for (A) by normalizing fold change (FC) to the average $\mathrm{FC}$ of $(\mathrm{C})$ for each splicing event. For amplicon spanning exons 4-5 in $A O X 1$ (Supplementary Table 1), the calculated FC (A)/average
FC (C) value is less than $1(0.47)$, indicating decreased exon 5 inclusion in Normal vs. $\mathrm{HCV}+$. This is finally reported as $-1 / 0.47=-2.1$, as a negative number (Table $5 \mathrm{~B})$. For $S A A 1$, the reported positive SI number (9.12) indicates increased exon 3 inclusion in Normal vs. HCV+. Each sample was measured in triplicate and values were reported as average.

\section{Immunohistochemistry}

Study tissue blocks (24 samples, including 3 normal; $3 \mathrm{HCV}+, 3 \mathrm{HCCN}$ and $3 \mathrm{HCV}+/ \mathrm{HCC}$ for $\mathrm{CA}$ and $\mathrm{AA}$, respectively) were selected after histopathologic review by pathologists. Three 4-tissue sections were selected from each block (total $=96$ tissue slides). All of the tissue slides were treated to heat induced epitope retrieval (HIER) in a decloaker (BIocare Inc.) using HIER-L solution (citrate buffer, $\mathrm{pH}$ 6.0, Thermo Fisher). Detection for serum amyloid A1 protein (SAA1) and hepatocyte nuclear factor 4-alpha (HNF4 $\alpha$ ) isoforms was performed by incubating slides in a rabbit anti-mouse antibody (SAA1, Clone \# 902738, R\&D Systems, Cat \# MBA30191, dilutions 1:50), (P1/P2-HNF4 $\alpha$, Clone \# H1415, R\&D Systems, Cat \# PP-H1415-00, dilutions 1:100) or (P1-HNF4 $\alpha$, Clone \# K9219, Cat \# PP-K9218-00, dilutions 1:100) overnight at $4{ }^{\circ} \mathrm{C}$ followed by incubation in a horseradish peroxideconjugated anti-rabbit antibody, then developing with 3,3'-diaminobenzidine tetrahydrochloride chromogen. For negative control, the primary antibodies were replaced with PBS. Liver sections were used as positive controls. Staining reactivity for each protein/tissue slide was graded by two pathologists (MMY and SB) as consensus using a semi-quantitative scoring system $(0-4)$ as previously reported [58]. The staining reactivity of 3-4 tissue slides was plotted for SAA1, P1/P2- and P1- HNF4 $\alpha$.

\section{Pathways, functional enrichment and interactive network analysis}

Gene networks and canonical pathways representing key genes were identified through the use of QIAGEN'S Ingenuity Pathway Analysis software (IPA, QIAGEN Redwood City, www.qiagen.com/ingenuity, content version 18841524 , release date $06 / 26 / 2014$ ) as previously reported [12]. Briefly, the data sets containing gene identifiers and corresponding fold change and $p$-values were uploaded into the web-delivered application and each gene identifier was mapped to its corresponding gene object in the IPA software. Fisher's exact test was performed to calculate a $P$-value assigning probability of enrichment to each biological function and canonical pathway within the IPA library.

\section{Statistical analysis}

The data were expressed as mean $\pm \mathrm{SE}$, and analyzed with the Student's $t$-test between two groups. Changes 
were considered statistically significant if the $P$-value was $<0.05$.

\section{Ethics statement}

Washington State University (WSU) Office of Research Assurances has found that the study is exempt from the need for the Institutional Research Board (IRB) approval. Thirty-six snapped frozen tissue samples (12 included in the original analysis and 24 for target validation study), as well as 25 tissue sections from formalin-fixed paraffin-embedded blocks were obtained from the IRB approved University of Kansas Medical Center Liver Center Tissue Bank. All specimens with anonymized identifiers were histopathologically confirmed by a pathologist.

\section{Abbreviations}

HCV: Hepatitis C virus; HCC: Hepatocellular carcinoma; HTA2.0: Human Transcriptome Array 2.0; $\mathrm{HCV}+$ : HCV positive cirrhotic liver; $\mathrm{HCV}+\mathrm{HCC}$ : HCV positive liver tumor; HCCN: Tumor adjacent normal tissue; CA: Caucasian American; AA: African American; AS: Alternative splicing; DEGs; Differentially expressed genes; IPA: Ingenuity pathway analysis; qRT-PCR: Quantitative real-time-PCR; FC: Fold Change; SI: Splicing Index; PSR: Probeset Ratio; IHC: immunohistochemistry.

\section{Author contributions}

Conceived and designed the experiments: SSD, MMY. Performed IHC study: MMY, SB. Contributed reagents/materials: SSD, BR. Analyzed the data: SSD, MMY, SB, ND. Wrote the paper: MMY, SSD. All authors read and approved the final version of the manuscript.

\section{ACKNOWLEDGMENTS}

The authors would like to thank University of Kansas Medical Center - Liver Center Tissue Bank for providing us with tissue samples. We thank Mr. Ryan Maynard for his assistance with HTA2.0 data analysis and TAC2.0 software. The authors are grateful for the excellent technical assistance of Ms. Zahra Afsharinejad and Ms. Kelly Hudkins. The critical review of the manuscript by Dr. Theo Bammler is greatly appreciated.

\section{CONFLICTS OF INTEREST}

The authors declare that they have no conflicts of interest.

\section{FUNDING}

Not applicable.

\section{REFERENCES}

1. Yeh MM, Yeung RS, Apisarnthanarax S, Bhattacharya R, Cuevas C, Harris WP, Hon TL, Padia SA, Park JO, Riggle KM, Daoud SS. Multidisciplinary perspective of hepatocellular carcinoma: A Pacific Northwest experience. World J Hepatol. 2015; 7:1460-1483.

2. Edlin BR. Perspective: test and treat this silent killer. Nature. 2011; 474: S18-S19.

3. Jacobson IM, Davis GL, El-Serag H, Negro F, Trépo C. Prevalence and challenges of liver diseases in patients with chronic hepatitis $\mathrm{C}$ virus infection. Clin Gastroenterol Hepatol. 2010; 8:924-33.

4. Gonzalez-Grande R, Jimenez-Perez M, Gonzalez Arjona, Mostazo Terres J. New approaches in the treatment of hepatitis C. World J Gastroenterol. 2016; 22:1421-32.

5. Chhatwal J, Wang X, Ayer T, Kabiri M, Chung RT, Hur C, Donohue JM, Roberts MS, Kanwal F. Hepatitis C disease burden in the United States in the area of oral directingacting antivirals. Hepatology. 2016; 64:1442-14450.

6. DeSantis C, Naishadham D, Jemal A. Cancer statistics for African Americans, 2013. CA Cancer J Clin. 2013; 63:151-166.

7. Saab S, Jackson C, Nieto J, Francois F. Hepatitis C in African Americans. Am J Gastroenterol. 2014; 109:1576-84.

8. Trooskin SB, Navarro VJ, Winn RJ, Axelrod DJ, McNeal AS, Velez M, Herrine SK, Rossi S. Hepatitis $\mathrm{C}$ risk assessment, testing and referral for treatment in urban primary care: role of race and ethnicity. World $\mathrm{J}$ Gastroenterol. 2007; 13:1074-8.

9. Su F, Green PK, Berry K, Ioannou GN. The association between race/ethnicity and the effectiveness of direct antiviral agents for hepatitis $\mathrm{C}$ virus infection. Hepatol. 2017; 65:426-438.

10. Artinyan A, Mailey B, Sanchez-Luege N, Khalili J, Sun CL, Bhatia S, Wagman LD, Nissen N, Colquhoun SD, Kim J. Race, ethnicity, and socioeconomic status influence the survival of patients with hepatocellular carcinoma in the United States. Cancer. 2010; 116:1367-77.

11. Daoud SS. Hepatitis C pharmacogenetics: possible solutions for an existing problem. J Pharmacogenomics Pharmacoproteomics. 2013; 4:2.

12. Dillon ST, Bhasin MK, Feng X, Koh DW, Daoud SS. Quantitative proteomic analysis in $\mathrm{HCV}$-induced $\mathrm{HCC}$ reveals sets of proteins with potential significance for racial disparity. J Transl Med. 2013; 11:239.

13. Ioannou GN, Dominitz JA, Weiss NS, Heagerty PJ, Kowdley KV. Racial differences in the relationship between hepatitis C infection and iron stores. Hepatology. 2003; 37:795-801.

14. Samantray J, Zambare S, Seyoum B, Abou-Samra AB. Glucose control and lipid metabolism in African American patients with type 2 diabetes mellitus and chronic hepatitis C viral infection. Endocr Pract. 2011; 17: 363-8. 
15. Mogilenko DA, Dizhe EB, Shavva VS, Lapikov IA, Orlov SV, Perevozchikov AP. The role of the nuclear receptors HNF4 alpha, PPAR alpha, and LXRs in the TNF alpha-mediated inhibition of human Apolipoprotein A-1 gene expression in HepG2 cells. Biochemistry. 2009; 48:11950-60.

16. Fang B, Mane-Padros D, Bolotin E, Jiang T, Sladek FM. Identification of a binding motif specific to HNF4 by comparative analysis of multiple nuclear receptors. Nucleic Acids Res. 2012; 40:5343-5356.

17. Hatziapostolou M, Polytarchou C, Aggelidou E, Drakaki A, Poultsides GA, Jaeger SA, Ogata H, Karin M, Struhl K, Hadzopoulou-Cladaras M, Iliopoulos D. An HNF4 $\alpha$-miRNA inflammatory feedback circuit regulates hepatocellular carcinoma. Cell. 2011; 147:1233-47.

18. Bonzo JA, Ferry CH, Matsubara T, Kim JH, Gonzalez FJ. Suppression of hepatocyte proliferation by hepatocyte nuclear factor $4 \alpha$ in adult mice. J Biol Chem. 2012; 287:7345-56.

19. Venables JP. Aberrant and alternative splicing of cancer. Cancer Res. 2004; 64:7647-7654.

20. Pal S, Gupta R, Davuluri RV. Alternative transcription and alternative splicing in cancer. Pharmacol Therap. 2012; 136:283-294.

21. Biamonti G, Catillo M, Pignataro D, Montecucco A, Ghigna C. The alternative splicing side of cancer. Semin Cell Dev Biol. 2014; 32:30-36.

22. Pan Q, Shai O, Lee LJ, Frey BJ, Blencowe BJ. Deep surveying of alternative splicing complexity in the human transcriptome by high-throughput sequencing. Nat Genet. 2008; 40:1413-1415.

23. Wang ET, Sandberg R, Luo S, Khrebtukova I, Zhang L, Mayr C, Klingsmore SF, Schroth GP, Burge CB. Alternative isoform regulation in human tissue transcriptomes. Nature. 2008; 456:470-476.

24. Hanoun N, Bureau C, Diab T, Gayet O, Dusetti N, Selves J, Vinel JP, Buscail L, Cordelier P, Torrisani J. The SV2 variant of KLF6 is downregulated in hepatocellular carcinoma and displays anti-proliferative and pro-apoptotic functions. J Hepatol. 2010; 53:880-8.

25. Shi Y, Lv G, Chu Z, Piao L, Liu X, Wang T, Jiang Y, Zhang P. Identification of natural splice variants of SAMHD1 in virus-infected HCC. Oncol Rep. 2014; 31:687-92.

26. Bauza G, Miller G, Kaseje N, Wang Z, Sherburne A, Agarwal S, Burke PA. Injury-induced changes in liver specific transcription factors HNF-1 $\alpha$ and HNF-4 $\alpha$. J Surg Res. 2012; 175:298-304.

27. Yi Q, Tang L. Alternative spliced variants as biomarkers of colorectal cancer. Curr Drug Metab. 2011; 12:966-74.

28. Pavlidou A, Kroupis C, Dimas K. Association of survivin splice variants with prognosis and treatment of breast cancer. World J Clin Oncol. 2014; 5:883-94.

29. Sun F, Indran IR, Zhang ZW, Tan MH, Li Y, Lim ZL, Hua R, Yang C, Soon FF, Li J, Xu HE, Cheung E, Yong EL.
A novel prostate cancer therapeutic strategy using icaritinactivated arylhydrocarbon-receptor to co-target androgen receptor and its splice variants. Carcinogenesis. 2015; 36:757-68.

30. Ji YR, Kim HJ, Bae KB, Lee S, Kim MO, Ryoo ZY. Hepatic serum amyloid A1 aggravates T cell-mediated hepatitis by inducing chemokines via Toll-like receptor 2 in mice. J Biol Chem. 2015; 290:12804-11.

31. Olteanu S, Kandel-Kfir M, Shaish A, Almog T, Shemesh S, Barshack I, Apte RN, Harats D, Kamari Y. Lack of Interleukin-1 $\alpha$ in Kupffer cells attenuates liver inflammation and expression of inflammatory cytokines in hypercholesterolaemic mice. Dig Liver Dis. 2014; 46:433-9.

32. Hansen MT, Forst B, Cremers N, Quagliata L, Ambartsumian N, Grum-Schwensen B, Klingelhöfer J, Abdul-Al A, Hermann P, Osterland M, Stein U, Nielsen $\mathrm{GH}$, Scherer PE, et al. A link between inflammation and metastasis: serum amyloid A1 and A3 induce metastasis, and are targets of metastasis-induced S100A4. Oncogene. 2015; 34:424-35.

33. Werynska B, Pula B, Muszczynska-Bernhard B, Gomulkiewicz A, Piotrowska A, Prus R, PodhorskaOkolow M, Jankowska R, Dziegiel P. Metallothionein 1F and 2A overexpression predicts poor outcome of non-small cell lung cancer patients. Exp Mol Pathol. 2013; 94:301-8.

34. He X, Wang Y, Zhang W, Li H, Luo R, Zhou Y, Liao CL, Huang H, Lv X, Xie Z, He M. Screening differential expression of serum proteins in AFP-negative HBV-related hepatocellular carcinoma using iTRAQ-MALDI-MS/MS. Neoplasma. 2014; 61:17-26.

35. Yan DW, Fan JW, Yu ZH, Li MX, Wen YG, Li DW, Zhou CZ, Wang XL, Wang Q, Tang HM, Peng ZH. Downregulation of metallothionein $1 \mathrm{~F}$, a putative oncosuppressor, by loss of heterozygosity in colon cancer tissue. Biochim Biophys Acta. 2012; 1822:918-26.

36. Semmo N, Weber T, Idle JR, Beyoglu D. Metabolomics reveals that aldose reductase activity due to AKR1B10 is upregulated in hepatitis $\mathrm{C}$ virus infection. J Viral Hepat. 2015; 22:617-24.

37. Ha SY, Song DH, Lee JJ, Lee HW, Cho SY, Park CK. High expression of aldo-keto-reductase $1 \mathrm{~B} 10$ is an independent predictor of favorable prognosis in patients with hepatocellular carcinoma. Gut Liver. 2014; 8:648-54.

38. Matkowskyj KA, Bai H, Liao J, Zhang W, Li H, Rao S, Omary R. Yang GY. Aldoketoreductase family 1B10 (AKR1B10) as a biomarker to distinguish hepatocellular carcinoma from benign liver lesions. Hum Pathol. 2014; 45:834-43.

39. Sato S, Genda T, Hirano K, Tsuzura H, Narita Y, Kanemitsu Y, Kikuchi T, Iijima K, Wada R, Ichida T. Up-regulated aldo-keto reductase family 1 member $\mathrm{B} 10$ in chronic hepatitis $\mathrm{C}$ : association with serum alpha-fetoprotein and hepatocellular carcinoma. Liver Int. 2012; 32:1382-90. 
40. Jablonowska E, Wojcik K, Koslinska-Berkan E, Szymanska B, Omulecka A, Piekarska A. Expression of selected genes in liver biopsy specimen in relation to early virological response in patients with chronic hepatitis $\mathrm{C}$ with $\mathrm{HCV}$ mono- and HIV/HCV co-infection. Arch Virol. 2014; 159:1365-71.

41. Langhans B, Kramer B, Louis M, Nischalke HD, Huneburg R, Staratschek-Jox A, Odenthal M, Manekeller S, Schepke M, Kalff J, Fischer HP, Schultze JL, Spendgler U. Intrahepatic IL-8 producing Foxp3+CD4+ regulatory $\mathrm{T}$ cells and fibrogenesis in chronic hepatitis C. J Hepatol. 2013; 59:229-35.

42. Ali FT, Ali MA, Elgizawy MM, Elsawy AM. Secreted phosphoprotein 1 promoter genetic variants are associated with the response to pegylated interferon $\alpha$ plus ribavirin combination therapy in Egyptian patients with chronic hepatitis C virus infection. Gut Liver. 2015; 9:516-10.

43. Liu X, Chi X, Gong Q, Gao L, Niu Y, Chi X, Cheng M, Si Y, Wang M, Zhong J, Niu J, Yang W. Association of serum level of growth differentiation factor 15 with liver cirrhosis and hepatocellular carcinoma. PLoS One. 2015; 10: $\mathrm{e} 0127518$.

44. Wandrer F, Falk C, John K, Skawran B, Manns MP, Schulze-Osthoff K, Bantel H. Interferon-mediated cytokine induction determines sustained virus control in chronic HCV infection. J Infect Dis. 2016; 213:746-54.

45. Cai Z, Zeng Y, Xu B, Gao Y, Wang S, Zeng J, Chen L, Huang A, Liu X, Liu J. Galectin-4 serves as a prognostic biomarker for the early recurrence/metastasis of hepatocellular carcinoma. Cancer Sci. 2014; 105:1510-7.

46. Yuan SX, Tao QF, Wang J, Yang F, Liu L, Wang LL, Zhang J, Yang Y, Liu H, Wang F, Sun SH, Zhou WP. Antisense long non-coding RNA PCNA-ASI promotes tumor growth by regulating proliferating cell nuclear antigen in hepatocellular carcinoma. Cancer Lett. 2014; 349:87-94.

47. Ho SM, Cheong A, Lam HM, Hu WY, Shi GB, Zhu X, Chen J, Zhang X, Mededovic M, Leung YK, Prins GS. Exposure of human prostaspheres to bisphenol A epigenetically regulates SNORD family noncoding RNAs via histone modification. Endocrinology. 2015; 156:3984-95.

48. Askarian-Amiri ME, Crawford J, French JD, Smart CE, Smith MA, Clark MB, Ru K, Mercer TR, Thompson ER, Lakhani SR, Vargas AC, Campbell IG, Brown MA, et al. SNORD-host RNA Zfas1 is a regulator of mammary development and a potential marker for breast cancer. RNA. 2011; 17:878-91.

49. Bauza G, Miller G, Kaseje N, Wang Z, Sherburne A, Agarwal S, Burke PA. Injury-induced changes in liver specific transcription factors HNF-1 $\alpha$ and HNF $4 \alpha$. J Surg Res. 2012; 175:298-304.

50. Hwang-Verslues WW, Sladek FM. HNF4a role in drug metabolism and potential drug target? Curr Opin Pharmacol. 2010; 10:698-705.

51. Tanaka T, Jiang S, Hotta H, Takano K, Iwanari H, Sumi K, Daigo K, Ohashi R, Sugai M, Ikegame C, Umezu H, Hirayama Y, Midorkawa Y, et al. Dysregulated expression of P1 and P2 promoter-deriven hepatocyte nuclear factor $4 \alpha$ in the pathogenesis of human cancer. J Pathol. 2006; 208:662-672.

52. Briancon N, Baily N, Clotman F, Jacquemin P, Lemaigre FP, Weiss MC. Expression of the alpha7 isoform of hepatocyte nuclear factor (HNF) 4 is activated by HNF6/OC-2 and HNF1 and repressed by HNF4alpha 1 in the liver. J Biol Chem. 2004; 279:33398-408.

53. Roberts L, Bowers J, Sensinger K, Lisowski A, Getts $\mathrm{R}$, Anderson MG. Identification of methods for use of formalin-fixed, paraffin-embedded tissue samples in RNA expression profiling. Genomics. 2009; 94:341-8.

54. Pillai R, Deeter R, Rigl CT, Nystrom JS, Miller MH, Buturovic L, Henner WD. Validation and reproducibility of a microarray-based gene expression test for tumor identification in formalin-fixed, paraffin-embedded specimens. J Mol Diagn. 2011; 13:48-56.

55. de la Grange P, Gratadou L, Delord M, Dutertre M, Aubonuf D. Splicing factor and exon profiling across human tissues. Nucleic Acids Res. 2010; 38:2828-38.

56. Pfaffl MW. A new mathematical model for relative quantification in real-time RT-PCR. Nucleic Acids Res. 2001; 29: 2003-2007.

57. Vandenbroucke II, Vandesompele J, De Paepe A, Messiaen L. Quantification of splice variants using real-time PCR. Nucleic Acid Res. 2001; 29:e68-e69.

58. Chan ES, Yeh MM. The use of immunohistochemistry in liver tumors. Clin Liver Dis. 2010; 14:687-703. 